NOTICE: this is the author's version of a work that was accepted for publication in Lingua. Changes resulting from the publishing process, such as peer review, editing, corrections, structural formatting, and other quality control mechanisms may not be reflected in this document. Changes may have been made to this work since it was submitted for publication. A definitive version is later to be published in Lingua, doi:10.1016/j.lingua.2012.03.004 


\title{
Final devoicing and vowel lengthening in Friulian: a representational approach
}

\author{
Pavel Iosad \\ Center for Advanced Study in Theoretical Linguistics (CASTL) \\ University of Troms $\phi$ \\ Troms $\phi 9037$ \\ Norway
}

\begin{abstract}
This paper proposes an account of final devoicing in Friulian which relies on contrastive feature specification and feature geometry to explicate the connection between final devoicing and vowel lengthening. It is proposed that obstruents which are the outcome of final devoicing are phonologically distinct from true voiceless obstruents, being completely unspecified for laryngeal features. It is argued that the representational deficiency of such delaryngealized obstruents is directly connected to their inability to license a mora, which opens the way to vowel lengthening. More generally, the paper shows how feature geometry may be adapted to capture the effects of contrastive specification and express markedness relations, and proposes a novel approach to hierarchies involving the sonority of coda segments.
\end{abstract}

Keywords: final devoicing, moraic theory, sonority hierarchy, feature geometry, Romance languages

The present paper has two purposes. Empirically, it focuses on final devoicing in Friulian and on the connection between final devoicing and vowel lengthening. Its aim is to account both for the phonetic phenomena involved in final devoicing and for the fact that stressed vowels are lengthened before devoiced obstruents (but only in a word-final syllable). From a theoretical perspective, the paper takes up several strands of recent research into markedness relations. I argue that feature specifications should be assigned solely on the basis of phenomena attested within

Email address: pavel.iosad@uit.no (Pavel Iosad) 


\begin{tabular}{|c|c|c|c|c|c|c|c|c|c|c|}
\hline Manner & \multicolumn{2}{|c|}{ Labial } & Dental & \multicolumn{2}{|c|}{ Alveolar } & Postalveolar & \multicolumn{2}{|c|}{ Palatal } & \multicolumn{2}{|c|}{ Velar } \\
\hline Stop & $\mathrm{p}$ & $\mathrm{b}$ & $\mathrm{t}$ & & & & $\mathrm{c}$ & $\mathrm{J}$ & $\mathrm{k}$ & $g$ \\
\hline Fricative & $\mathrm{f}$ & $\mathrm{v}$ & & $\mathrm{S}$ & & (3) & & & & \\
\hline Nasal & & $\mathrm{m}$ & & & 1 & & & $\mathrm{n}$ & & y \\
\hline Affricate & & & ts $\mathrm{dz}$ & & & $\widehat{d} \sqrt{3}$ & & & & \\
\hline Approximant & & $\mathrm{w}$ & & & & & & $\mathrm{j}$ & & \\
\hline Rhotic & & & & & r & & & & & \\
\hline Lateral & & & & & 1 & & & & & \\
\hline
\end{tabular}

Table 1: The consonantal inventory of Central Friulian

the language at hand, and show how feature geometry can be used to reproduce the effects of both a hierarchy of contrastive features (Dresher, 2003, 2009; Hall, 2007) and de Lacy's (2006) CoMP theory of markedness. Further, I discuss how Friulian data necessitate the amendment of existing proposals with regard to the universality of hierarchies enforcing higher sonority of coda consonants.

The organization of the paper is as follows. In section 1 I present the Friulian data which form the empirical basis of the paper. Section 2 presents the assumptions I make in order to analyse these data, and the analysis itself is presented in section 3. In section 4 I compare the proposed account with some of those previously proposed for the phenomena at hand and discuss several conceptual issues. Section 5 is a brief conclusion.

\section{Final devoicing and vowel lengthening in Friulian}

In this paper I concentrate on final devoicing in Friulian, with a focus on the best-described Central varieties; among useful sources are Francescato (1966); Vanelli (1979); Frau (1984); Hualde (1990); Repetti (1992); Baroni and Vanelli (2000); Finco (2009). An overview of relevant facts in other dialects can be found in Repetti (1992); Videsott (2001), and diachronic commentary is provided by Morin (1992, 2003); Loporcaro (2007, 2011a).

\subsection{The inventories}

The consonantal inventory of Central Friulian is shown in table 1 (Miotti, 2002; Finco, 2009). The presentation is slightly more surface-oriented than in the explicitly phonological chart of Finco (2009); for instance, [ $\mathrm{y}]$ is included despite being noncontrastive (see below). 


\begin{tabular}{lcccccc}
\hline & \multicolumn{2}{c}{ Front } & \multicolumn{2}{c}{ Central } & \multicolumn{2}{c}{ Back } \\
\cline { 2 - 6 } Height & Short & Long & Short & Long & Short & Long \\
\hline High & i & i: & & & u & u: \\
Mid-high & e & e: & & & o & o: \\
Mid-low & $\varepsilon$ & $\varepsilon:$ & & & o & o: \\
Low & & & a & a: & & \\
\hline
\end{tabular}

Table 2: Stressed vowels in Central Friulian

The inventory is quite standard for Romance languages; however, an important point is the presence of both palatal stops $/ \mathrm{c} \mathrm{J} /$ and postalveolar affricates.

The consonant $[\mathrm{g}]$ is not contrastive, being only found as a coda allophone of some (Miotti, 2002) or all (Baroni and Vanelli, 2000; Finco, 2009) nasals, though other nasals may appear in the coda if they share place specification with the following segment. ${ }^{1}$

The vowel inventory of stressed syllables in Central Friulian is shown in table 2. The monophthongal pronunciation of long vowels is a characteristic of this dialect group; other Friulian varieties often show various diphthongs. ${ }^{2}$ The long mid-low vowels $/ \varepsilon: 0: /$ are said to be peripheral to the system and often merge with the mid-high /e: o:/.

In unstressed position, all long vowels are excluded, as are the mid-low /ع o/, thus presenting the classic five-vowel /i u e o a/ system.

\footnotetext{
${ }^{1}$ An anonymous reviewer suggests that the segment transcribed as $[\mathrm{g}]$ in coda position not before a consonant might in fact simply be nasalization, as found, for instance, in Japanese (e. g. Trigo, 1988), and that it can be phonologically interpreted as a placeless nasal. I am not aware of any detailed phonetic study of this matter for Friulian; Miotti (2002) states that the coda nasal is velar, but does not provide instrumental data and also mentions a "partially assimilated velar articulation", which might well correspond to what the reviewer suggests. I do find this suggestion very plausible. As long as we accept that phonologically the nasalization represents a nasal segment, this does not have a significant bearing on the analysis. I keep the transcription to retain ease of comparison with the sources.

${ }^{2}$ See, for instance, Miotti (2007). The long monophthongs of Central Friulian are a secondary development with respect to these diphthongs, and indeed still described as phonetically diphthongized by Miotti (2002).
} 


\subsection{Vowel length and codas}

Long vowels in Central Friulian are restricted to the final or penultimate stressed syllable. Vowels in antepenultimate syllables, even in the rare cases when they are stressed, are never long. Moreover, long vowels in penultimate syllables are also relatively rare, and in fact not present in all varieties of Friulian. Some examples are shown in (1).
a. [ma:ri]
b. [vo:li]
c. [fra:di]
'mother' (Vulgar Latin MATREM)
'eye' (Vulgar Latin OC(U)LUM)
'brother' (Vulgar Latin FRATREM)

The existence of such examples is important because it establishes beyond reasonable doubt the existence of a vowel length contrast in the relevant varieties: cf. the examples in (2), which show the existence of a contrast between ' $\mathrm{CV}: \mathrm{CV}$ and 'CVCV words.
a. ['lade]
b. ['pale]
'gone (fem. sg.)'
'shovel'

A very different picture is found in word-final (stressed) syllables. In word-final open syllables, the vowel length contrast is neutralized in Central Friulian in favour of the short vowel (Miotti, 2002; Finco, 2009). Thus, while some dialects still retain a contrast between forms such as ['di:] 'to say' (orthographically $d \hat{\imath}$ ) and ['di] 'day' (dì), or [can'ta:] 'to sing' (cjantâ) and [can'ta] '(s)he sang' (cjantà), in Central Friulian the stressed vowel in all these forms is phonologically short.

The most complex situation is found in word-final stressed closed syllables. The nature, and indeed the very presence of a vowel length contrast in this position is intricately related to the featural make-up of the coda.

The length contrast is undoubtedly present if the coda contains the lateral [1], as exemplified by the minimal pairs in (3).
a. (i) $\quad[$ 'val $]$
'valley'
(ii) $[$ 'va:l $]$
'(it) costs'
b. (i) ['mil $]$
'thousand'
(ii) $\quad[$ 'mi:l $]$
'honey'

There are several contexts where the contrast is neutralized. Specifically, only short vowels are allowed before coda nasals (including nasals as parts of clusters) and the postalveolar affricate $[\widehat{\mathrm{t}}]$ : 
(4)
a. ['maj]
'hand'
b. ['camp]
'field'
c. ['bratf]
'arm'

An exception from this generalization is found (only in some varieties; Yamamoto 1993) in some morphological contexts, prominently in the 1st and 3rd persons singular present indicative, for verbs with a zero suffix. In these forms, the vowel is long before $[\widehat{t}]$, a pattern otherwise disallowed in the language, as shown in (5):
a. [distru'dzi]
'to destroy'
b. [dist'ru:t?]
'(s)he destroys'

Vowels are normally short before coda clusters, as in (6-a). However, vowel length may be retained before clusters where the second consonant is the plural marker [s], as in (6-b) (Finco, 2009). ${ }^{3}$
a.
['gust]
'taste'
b. (i) ['lu:k]
'place'
(ii) $[$ 'lu:ks $] /[$ 'luks $]$
'places'

Conversely, short vowels are excluded from the position before a coda [r]. The sources are slightly contradictory: Miotti (2002) describes the neutralization as happening before word-final [r], as in (7), while Baroni and Vanelli (2000) adduce examples such as (8) and suggest that vowels are uniformly long even before nonfinal rhotics.

(7) $\quad[$ 'ca:r $]$

'cart' (cjar); 'dear' (cjâr)

(8) [spo:rk]

'dirty (masc. sg.)' (sporc)

However, Finco (2009) explicitly transcribes the same word as in (8) as ['spo'rk], with a phonetically half-long vowel. Normally phonetic half-length corresponds to phonological shortness, so Finco (2009) seems to be in agreement with Miotti (2002) on this point.

\footnotetext{
${ }^{3}$ However, Finco (2009, p. 57) notes that (my translation) "after a phonologically long vowel, there is in reality a strong tendency for codas to be monoconsonantal, even in the presence of morphological conditioning" ("daspò vocâl fonologjichementri lungje in realtât si à la fuarte tindince a realizâ une code monoconsonantiche, ancje in presincje di condizionaments morfologjics”).
} 
Finally, singleton obstruents present the most intriguing piece of the puzzle. Superficially (and certainly orthographically), vowel length is simply contrastive in this position, as the minimal pairs in (9) show.
a. (i) ['la:t
(ii) ['lat]
b. (i) ['bru:t $]$
(ii) ['brut]

'gone (masc.)' (lât)

'milk' (lat)

'string' (brût)

'ugly' (brut)

Thus, the distribution of vowel length is not predictable based on the surface context alone. However, a very robust generalization can be extracted: final voiceless obstruents that are preceded by long vowels are overwhelmingly those which appear as voiced when not word-final. This is illustrated in (10).
a. (i) $\quad[$ 'la:t $]$
(ii) ['lade]
b. (i) ['lat $]$
(ii) [la'ta]

'gone (masc.)'
'gone (fem.)'
'milk'
'to breastfeed'

The existence of examples such as (10-b-ii) shows that Friulian does not have a process of intervocalic voicing, and that the voiced stop in (10-a-ii) must be underlying. Thus, the distribution of vowel length in Friulian final stressed syllables before obstruents can be expressed as follows (Francescato, 1966; Haiman and Benincà, 1992; Baroni and Vanelli, 2000):

(11) Stressed vowels are long in final syllables before underlyingly voiced obstruents; laryngeal alternation always leads to vowel alternation

Following most of the existing literature (the exception is Repetti, 1994, see below section 4.1), I assume that this represents an instance of vowel lengthening in final syllables and not shortening in non-final syllables. This certainly has to be the default assumption for those varieties where 'CV:CV words contrast with 'CVCV ones, since the supposed shortening is not surface-true.

One systematic exception is that vowels are not lengthened before underlyingly voiced affricates, obviously a corollary of the general lack of long vowels before affricates:
a. $\quad\left[\operatorname{mj} \varepsilon \widehat{\mathrm{d}_{3} \mathrm{e}}\right]$
b. ['mjet $\left.\int\right]$
'mid (fem. sg.)'
c. $*[$ 'mje:t] $]$
'mid (masc. sg.)' 
Similar alternations are known in Gallo-Italian varieties, such as Western Lombard, for instance Milanese (Sanga, 1988; Repetti, 1992; Prieto i Vives, 2000) and the dialect of Casale Corte Cerro (Weber Wetzel, 2002), as well as in GalloRomance, specifically in the French dialects of Alsace and Lorraine (Montreuil, 2010, with references). Some examples are given in (13).

a. Western Lombard (Casale Corte Cerro) (Weber Wetzel, 2002, p. 110)
(i) [ [dzi'lu:z] 'jealous (masc. sg.)'
(ii) $\left[\widehat{\mathrm{d}} \mathfrak{z}^{\mathrm{i}}\right.$ lu'ze $]$ 'jealous (fem. sg.) 4

b. Eastern Regional French (Montreuil, 2010, p. 156)
(i) $[$ fre:s $]$
'strawberry'
(ii) $[$ frezje $]$
'strawberry bush'

Long vowels that precede a word-final lateral can also alternate with a short vowel in a non-final syllable:
a. ['sa:l]
'salt'
b. ['sale]
'(s)he salts'

In the rest of the paper I demonstrate that if the alternating vowels are assumed to be a product of lengthening, an elegant account of the quantity facts is available in parallel Optimality Theory. Before I turn to the theoretical questions, however, I discuss more data that have a bearing on the phonological interpretation.

\subsection{Incomplete neutralization in final devoicing}

The phonetic implementation of voicelessness in word-final position was explored in detail by Baroni and Vanelli (2000). They set out to find whether the contrast between underlyingly voiced and voiceless obstruents is fully neutralized in this position.

Baroni and Vanelli (2000) find that the contrast is easily recoverable, not just from the vowel length facts, but also from other cues, some of which are related to the articulation of the consonant itself. They identify the following differences in the realization of word-final obstruents which are underlyingly voiced vis-à-vis lexically voiceless obstruents:

- Devoiced stops show weaker bursts than voiceless stops;

\footnotetext{
${ }^{4}$ I assume that the half-length mark in (13-a-ii) corresponds to a phonologically short vowel; for more discussion with reference to Friulian, see Finco $(2007,2009)$.
} 
- Devoiced stops are significantly shorter than voiceless stops, and of about the same duration as voiced stops.

They also point to certain differences in the realization of the stressed vowel before the two categories of stops:

- There is a statistically significant difference in vowel length: vowels before devoiced stops are on average more than twice as long as vowels before voiceless stops;

- There is a significant difference in the placement of pitch accents: before devoiced stops, the preceding vowel bears a HL tone, while vowels before voiceless stops are realized with a relatively late $\mathrm{H}$ peak;

Thus, devoiced stops are phonetically distinct from voiceless ones, and share certain traits with voiced stops which appear in non-word-final position (such as closure duration). At the same time devoiced stops are distinct from voiced stops, failing to exhibit voicing during the closure phase. Thus, at least phonetically neutralization of the laryngeal contrast in word-final position in Friulian is incomplete, similarly to what has been reported for other languages, such as Catalan (Dinnsen and Charles-Luce, 1984; Charles-Luce and Dinnsen, 1987), Polish (Slowiaczek and Dinnsen, 1985), Russian (Pye, 1986; Shrager, 2002), and Dutch (Warner et al., 2004; Ernestus and Baayen, 2006); a recent overview is found in van Oostendorp (2008).

In addition, Baroni and Vanelli (2000) report that word-final voiceless stops are longer than word-internal voiceless stops, with the difference reaching statistical significance.

While instrumental data are hard to come by, descriptions of the Romance varieties which demonstrate alternations similar to the Friulian ones also mention incomplete neutralization. Sanga (1988) describes word-final voiced obstruents in Milanese as variably or incompletely voiced ${ }^{5}$ (variation is noted by other sources as well, for instance by Prieto i Vives, 2000; Morin, 2003). Weber Wetzel (2002, p. 70) describes the devoiced obstruents in Casale Corte Cerro as "generally intermediate between voiceless and voiced" ("generalmente... un suono intermedio fra sorda e sonora”), and Montreuil (2010, p. 156) lists sources describing incomplete neutralization (at least for stops) in Alsatian French.

\footnotetext{
5"In milanese, le consonanti finali mantengono la sonorità in maniera variabile... o restano sonore, o passano a sorde, o hanno una realizzazione intermedia." (Sanga, 1988, p. 295)
} 
In the next section I present some important theoretical assumptions behind the analysis to be presented in this paper. ${ }^{6}$

\section{Theoretical assumptions}

In this section I outline two important groups of assumptions that I will use in the analysis, namely those related to substance-free phonology and to feature geometry and stringent violation sets. Specifically, I give a brief overview of the substance-free approach to phonology I employ in this paper, and show that adopting geometrical featural representations allows for an account of segmental markedness that does not make recourse to additional assumptions such as de Lacy's (2006) multivalued features.

\subsection{Substance-free representations}

In this paper I use a substance-free approach to phonological representation and computation. Simply put, I assume that the physical realization of the elements of the phonological alphabet is irrelevant to the computation. In practice, this means the following:

- There is no universal set of substantive features. Instead, features are emergent from generalizations based on actual data from a given language. Features are therefore assigned to segments on a language-specific basis, relying on overt evidence from that language rather than on a priori generalizations with respect to the behaviour of phonological primitives: for similar approaches and discussion, see Morén (2006, 2007); Mielke (2007); Blaho (2008); Boersma and Hamann (2008); Boersma (2009); precursors to this line are found in structuralist thinking, e. g. Martinet (1955); Hjelmslev (1975). In practice, this means that phonetically similar segments in different languages are not guaranteed to have identical or even similar phonological representations, since the latter depend exclusively on phonological

\footnotetext{
${ }^{6}$ Some sources contain examples which seem to contradict the picture presented here. Most of these examples involve lengthening before underlying voiceless obstruents. Frau (1984, p. 72) gives isolated examples of alternations such as ['rors] 'red (masc. sg.)' $\sim$ ['rose] 'red (fem. sg.)'; the status of these forms and not least their provenance are not always clear (for instance, Baroni and Vanelli 2000, p. 17 quote the same pair as ['ros] ['rose] in line with expectations). I leave this matter aside here, not least because Frau (1984) does not make a distinction between voiceless and devoiced word-final stops, so a confident analysis is difficult to arrive at. In any case, given that the lengthening-and-devoicing pattern is productive (Baroni and Vanelli, 2000), such cases appear to be exceptional in some way. See also below section 3.3.3.
} 
behaviour. Thus, the present framework has numerous points of contact with work by scholars such as Avery and Rice (1989); Rice and Avery (1989); Rice (1996, 2003); Dresher (2003, 2009); Hall (2007). The approach also has a clear relationship to structuralist phonology (Trubetzkoy, 1939; Martinet, 1955), as discussed at length by Dresher (2009). Obvious connections also exist with various versions of Dependency Phonology, Government Phonology, and Element Theory (Anderson and Ewen, 1987; Harris and Lindsey, 1995; Backley, 2011) and with Schane's (1984) Particle Phonology. The insistence on phonology as a component with its own, domain-specific representations strongly echoes Foley's (1977) rejection of mainstream generative phonology as "transformational phonetics".

- Phonological computation is also substance-free, that is, blind to the realization of the elements it operates with. This means that phonetic plausibility, functional load and similar considerations do not play a rôle in determining whether a phonological process is allowed by phonological computation even though such considerations may well be driving acquisition and language change. In this respect, the approach is similar to that advocated by Reiss (2007); Hale and Reiss (2008), who also propose that restrictions on computation are oblivious to the nature of the elements participating in it.

- One consequence of feature assignment based on overt evidence is surface underspecification. If only those features for which overt phonological evidence exists are taken into consideration, some segments will not receive enough phonological specification to fully describe their phonetic behaviour. For instance, in many languages the vowels /o u/ do not show evidence for one of backness or roundness: even if one of these features establishes lexical contrast (e.g. backness to distinguish /o u/ from /i e/), the other can be phonologically inert (there is no rounding harmony, or alternations where the back vowels pattern with labials, etc.). The fact that such features are still "filled in" in phonetic realization requires a non-trivial, non-universal phonetics-phonology interface. I assume a modular split between phonetics and phonology, where the interface translates abstract phonological representations into representations specifying phonetic features (for an overview of interface theories, see Kingston 2007).

Another technical detail, namely the assumption of tiered autosegmental representations, has important consequences for the approach to markedness that I employ in this paper. These implications are the subject of the next section. 


\subsection{Markedness effects and feature geometry}

In this section I show that arboreal representations can reproduce the markedness effects which de Lacy (2006) has argued to be the product of a combination of universal feature specification and stringent constraint violation sets.

Assume a feature-geometrical representation that makes distinctions between root nodes, tier nodes and features. If markedness and faithfulness constraints are interpreted non-exhaustively (i. e. a markedness constraint against some structure [A] assigns a violation mark for all structures that contain [A], even if other elements are also present), the sets of violation marks assigned to geometric structures of varying sizes will stand in a subset ordering relation. This is demonstrated in (15) for markedness constraints, where a tuple notation signifies paths along the feature-geometrical tree, starting from the root node.

Subset ordering of violation sets: markedness const
\begin{tabular}{|l||c|c|c|}
\hline & $*$ Root & $*$ Lar & $*$ [voice] \\
\hline \hline a. $\langle$ Root $\rangle$ & $*$ & & \\
\hline b. $\langle$ Root, Lar $\rangle$ & $*$ & $*$ & \\
\hline c. $\langle$ Root, Lar,[voice] $\rangle$ & $*$ & $*$ & $*$ \\
\hline
\end{tabular}

Faithfulness constraints exhibit a similar effect.

Subset ordering of violation sets: faithfulness constraints

\begin{tabular}{|c|c|c|c|}
\hline$\langle$ Root,Lar,[voice] $\rangle$ & *MAX(Root) & MAX(Lar) & $\operatorname{MAX}([$ voice $])$ \\
\hline a. $\langle\emptyset\rangle$ & * & $*$ & * \\
\hline b. $\langle$ Root $\rangle$ & & $*$ & * \\
\hline c. $\langle$ Root,Lar $\rangle$ & & 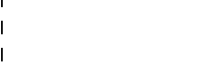 & $*$ \\
\hline d. $\langle$ Root,Lar,[voice] $\rangle$ & & 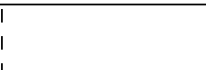 & $\begin{array}{l}1 \\
1\end{array}$ \\
\hline
\end{tabular}

Such ordered sets are familiar in recent Optimality Theoretic literature from work by de Lacy (2002, 2006, et passim), who calls them stringent violation sets. As he shows at length, sets of markedness and faithfulness constraints that have the property of forming such stringent violation profiles are superior to traditional constraints that only make reference to a single element, because the former allow us to formalize markedness hierarchies. De Lacy (2006) demonstrates that processes involving paradigmatic changes in markedness are severely restricted. 
In particular, he argues that elements can either become less marked along some hierarchy or be protected from a markedness-reducing process if they are highly marked themselves (Preservation of the Marked); increase of markedness along a hierarchy can only be compelled if it decreases markedness along some other hierarchy.

These are all welcome results, but they are achieved by de Lacy (2006) at the cost of assumptions that I suggest to be unnecessary. One such stipulation is the Markedness Reference Condition: stringent violation sets arise because there is a stipulation that constraints can only refer to a contiguous stretch on the hierarchy, starting with the most marked element. De Lacy (2006) stipulates this by fiat, while with feature geometry this is a natural consequence of geometric organization.

In addition, de Lacy (2006) assumes that markedness hierarchies are crosslinguistically consistent, so that, for instance, [coronal] is universally less marked than [labial] but more marked than [glottal]. To formalize this, he assumes that markedness hierarchies themselves refer to multivalued features such as [Place], and that the mapping between values of multivalued features and more orthodox phonetically based ones is universal. Irrespective of whether the universality assumption is correct, the theory still requires an additional entity (multivalued features) to express markedness relationships among standard features, while feature geometry can reproduce the set ordering and thus markedness effects directly.

The idea that markedness equals structural size is of course not new; indeed this is arguably the original sense of the "mark" as used in the context of privative features by Trubetzkoy (1939). Many privative approaches have formalized decrease in markedness as deletion of structure, in particular in the context of Dependency Phonology (Anderson and Ewen, 1987), Element Theory (Harris and Lindsey, 1995) and related theories, cf. Harris (1997, 2005, 2009); Cyran (2010). In the context of Optimality Theory, the connection between contrast, markedness, and structural complexity has been pursued by Causley (1999). However, privative approaches generally operate only with a binary contrast (absence vs. presence of a feature), while feature geometry allows for ordering relations in bigger classes of structures, as argued by Causley (1999); Rice (2003). In this paper, I demonstrate an application of this approach in the context of Optimality Theory.

With these assumptions in hand, I now turn to the analysis of Friulian. 


\section{Analysis}

In this section I present a formal analysis of the data. I start with the representational assumptions which form the core of the proposal. In the second subsection, I sketch the analysis in standard autosegmental terms, and then I provide an account of the pattern within the tenets of Optimality Theory.

\subsection{Representational assumptions}

As outlined above in section 2, I espouse an approach to phonological representation which involves the non-trivial assignment of features to segments based on the latter's phonological activity. Specifically, I propose that in Friulian the phonological feature which distinguishes laryngeal state for obstruents is privative [voiceless]. ${ }^{7}$ In this section I show how this assumption permits us to account for both the realization of laryngeal contrasts in word-final position and the behaviour of segment classes with respect to moraicity (and hence the length of the preceding vowel).

The feature-geometrical approach I use here is broadly familiar from earlier representational work; some examples are Rice and Avery (1989); Avery (1996); Mascaró (1987); Lombardi (1995b). A novel aspect of the proposed approach is the use of the [voiceless] feature, which reverses the markedness relations usually assumed to hold in voice-based systems.

I propose that Friulian obstruents can have one of the three representations shown in (17). I assume the computational system only allows laryngeally specified (i.e. voiced and voiceless) obstruents in most positions; however, laryngeally unspecified obstruents are possible in certain prosodic environments. Sonorants are also unspecified for laryngeal features, since these are not contrastive for this part of the inventory: in terms of Dresher's (2009) contrastive hierarchy, features which make sonorants distinct, such as manner, are higher on the hierarchy than laryngeal features.

\footnotetext{
${ }^{7}$ This feature is similar to the H element in Element Theory (Harris and Lindsey, 1995). See also Blaho (2008) for a [voiceless] feature outside of the context of Element Theory.
} 


$\begin{array}{ccc}\times & \times & \times \\ & \text { Lar } & \mid \\ & & \text { Lar } \\ & & \text { [voiceless] } \\ & \text { Voiced } & \text { Voiceless }\end{array}$

As demonstrated in section 2.2, these representations mean that unspecified obstruents are the least marked type, while voiceless obstruents are the most marked. This predicts that unspecified obstruents can undergo markedness reduction, while voiceless obstruents can resist it (by Preservation of the Marked). Moreover, this ternary contrast in phonological representations serves to account for the ternary contrast in the phonetics discussed in section 1.3. The mechanics of the analysis are shown in the next section.

\subsection{The autosegmental analysis}

The essence of the proposed analysis is as follows: final devoicing in Friulian affects only the less marked (voiced) obstruents, while voiceless obstruents resist it. Therefore, final devoicing is not an instance of final laryngeal neutralization (Iverson and Salmons, 2011) but rather selective reduction of markedness in wordfinal position. Vowel lengthening is due to pressure to create a bimoraic foot, as in the analysis of Milanese by Prieto i Vives (2000) or of Miogliola Ligurian by Ghini (2001a). Only laryngeally specified obstruents can support a mora, while delaryngealized obstruents cannot provide the second branch of this binary foot, which has to come from a long vowel. In the case of voiceless obstruents, a moraic coda is possible, and thus there is no pressure for the vowel to lengthen.

A final stressed syllable closed by a voiceless obstruent is shown in (18). Since final laryngeal neutralization is not applicable, the coda obstruent is able to project a mora, which can form part of a binary foot. Consequently, it is sufficient for the vowel to project just one mora. ${ }^{8}$

\footnotetext{
${ }^{8}$ For the sake of simplicity, I omit the syllable node in these representations, and silently assume that binarity constraints may make reference to moraic structure irrespective of the syllabic affiliation of the morae involved.
} 
(18) Voiceless coda obstruent supports a mora

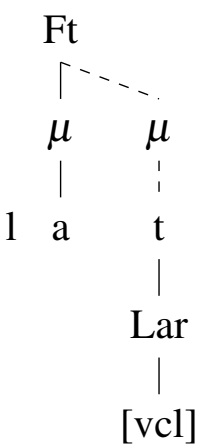

In the case of devoiced obstruents, shown in (19), the Laryngeal node is absent, and thus the segment is unable to support a mora. Therefore, a second vocalic mora is inserted to satisfy foot bimoraicity, producing vowel lengthening. The delinking of the Laryngeal node produces the "devoicing" effect, creating a phonological representation that is different from that of lexical voiced stops.

(19) Devoiced coda obstruent cannot project a mora

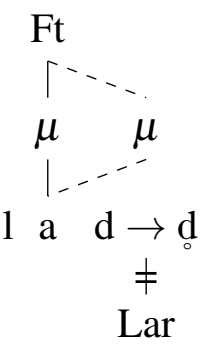

In the case of non-final stress, a binary foot can span two syllables, so neither coda moraicity nor vowel lengthening are necessary for binarity. Therefore, there is no difference between stressed vowels before different kinds of obstruents in non-final stressed syllables. Example (20) shows the derivation.

(20) Non-final stress allows for a bisyllabic foot

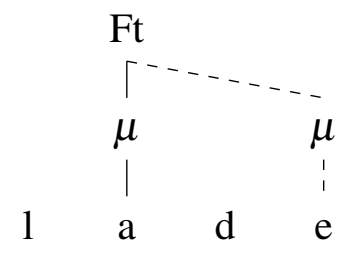


In the next section, I demonstrate how the basic facts can be derived in terms of Optimality Theory (Prince and Smolensky, 1993).

\subsection{OT analysis: final-syllable lengthening}

I start this subsection by presenting the main constraints involved in the analysis. Most of them are relatively orthodox; however, I also make a proposal to amend one constraint type familiar from the literature.

- For faithfulness and markedness, I use the constraints MAX(A) and *A, where A can by any phonological element (i.e. a node or a feature). The constraints are interpreted non-exhaustively;

- Moraic markedness constraints: following Morén (2001), I assume a constraint schema which militates against the association of certain classes of segments with a mora. For instance $* \mu[$ nas] assigns a violation mark for each segment which both contains the feature or set of features representing nasals in Friulian and is associated with a mora;

- Moraic faithfulness constraints: again following Morén (2001), I assume a constraint MAXLINK- $\mu[\alpha]$, which penalizes the removal of underlying association lines between a mora and a segment bearing the feature or feature bundle $[\alpha]$. In particular, I follow Morén (2001) in making a distinction between MAXLINK- $\mu[\mathrm{C}]$ and MAXLINK- $\mu[\mathrm{V}]$, leaving aside the exact formalization of the divide between consonants and vowels;

- Binarity constraints: for the purposes of this analysis, I use FTBIN as a (moraic) minimality constraint. I also use $* \mu \mu \mu$ to militate against trimoraic syllables;

- Weight-by-position constraints: I propose to amend the weight-by-position schema. In standard theory, WEIGHT B Y POSITION is a constraint demanding that all coda segments must be moraic (cf. Morén, 2001). Differences in the moraicity of certain segment classes are then derived from the interaction of the single WEIGHT BY POSITION constraint with a markedness hierarchy regulating the sonority of segments in certain prosodic positions. Details of this latter differ across implementations: for instance, Prince and Smolensky (1993) propose a set of markedness constraints on syllable nuclei and margins; Morén (2001), following Zec (1988), argues that constraints against moraicity of sonority classes are arranged in a fixed ranking; 
and de Lacy (2006) proposes another markedness hierarchy which favours high-sonority codas. Below I discuss why this schema is problematic for the analysis of Friulian. I propose to parametrize WEIGHT BY POSITION to featural structure, and employ constraints such as WBP(Lar). These constraints penalize nonmoraic coda segments iff they contain the relevant feature or geometrical node, and are therefore vacuously satisfied by non-coda segments, as well as by coda segments lacking the relevant specification. I demonstrate why this approach is necessary in section 3.3.2, and provide more discussion in section 4.4;

- Delaryngealization in word-final position: I suggest that the analysis of Friulian requires markedness reduction in word-final position to derive from a "disalignment" constraint (e. g. Hall, 2009), which simply penalizes a token of $\langle$ Lar $\rangle$ at the right edge of a word;

- I also use an EXTRAMETRICALITY constraint, which I understand to militate against moraic segments in word-final position. Extrametricality is often understood in terms of the extrametricality of higher-order prosodic constituents visible in stress assignment, or in terms of phonotactics; however, this notion can be extended to require that word-final consonants not occupy a moraic coda position; for a recent overview, cf. Vaux and Wolfe (2009). ${ }^{9}$

We start by treading what should be familiar territory, namely sonorant weight. Throughout this paper, I operate with the useful distinction between coerced and distinctive weight introduced by Morén (2001). Coerced weight appears when moraic markedness constraints dominate faithfulness, making the surface distribution of moraicity entirely predictable from the syntagmatic context. Distinctive weight, on the other hand, arises from a faithfulness-over-markedness ranking, when underlying weight distinctions are reproduced on the surface rather than obscured by restrictions on surface moraicity. Morén (2001) argues that coerced, but not distinctive weight is subject to sonority restrictions, in that if some segment class is moraic in a language under given prosodic conditions due to weight coercion, then all more sonorous segment classes must also be moraic in the same environment. No such restrictions hold for distinctive weight. A major claim

\footnotetext{
${ }^{9}$ Alternatively, we can see the relevant type of extrametricality as adjunction to a prosodic node higher than the syllable coupled with the impossibility of morae outside syllables.
} 
in this paper is that coerced weight can also fail to obey the coda-sonority restrictions. In support of this proposal, I will demonstrate that the coda-sonority hierarchy is not obeyed by Friulian sonorants, and present an analysis in terms of relativized weight-by-position; then I will show that this analysis extends naturally to the facts of obstruent weight. However, before doing this, I consider the status of vowel length in Friulian.

\subsubsection{The status of vowel length}

As discussed above in section 1.2, vowel length in (Central) Friulian is largely predictable. In the analysis that follows, I concentrate on deriving this predictability in the relevant contexts. However, a discussion of the status of unpredictable vowel length is also in order. ${ }^{10}$

Long vowels in Friulian are only found in stressed ultima and penultima. I suggest than in penultima the existence of the contrast is due to a standard markedness-over-faithfulness ranking where MAX- $\mu$ dominates at least $* \mu$ (a general constraint against morae). The constraint $* \mu$ [cons], which militates against consonantal morae, cannot be ranked here, but contributes to harmonic bounding, as seen in (21).

MAX- $\mu \gg * \mu$ : ['marri] 'mother'
\begin{tabular}{|c||c|c|}
\hline \multicolumn{1}{|c|}{ marri } & MAX- $\mu$ & $* \mu$ \\
\hline \hline a. mai $\mu \mu_{\mu \mathrm{ri}}$ & & $* *$ \\
\hline b. $\quad \operatorname{ma}_{\mu} \mathrm{ri}$ & $* !$ & $*$ \\
\hline c. $\quad \operatorname{ma}_{\mu} \mathrm{r}_{\mu} \mathrm{i}$ & & $* *$ \\
\hline
\end{tabular}

In final syllables, the situation is in flux: some varieties allow a contrast and some neutralize it in favour of the short vowel. The neutralization of an underlying contrast must be the product of some markedness constraint; for reasons of focus I cannot consider the nature of this constraint in detail and use the provisional formulation *FINALLONGV. In dialects which preserve the length contrast, this constraint is ranked below MAX- $\mu$; however, it must still dominate FOOT BINARITY to ensure that short vowels are not lengthened in open stressed ultima (as I will argue they are in other cases).

\footnotetext{
${ }^{10}$ I thank a reviewer for raising this issue.
} 
a. No shortening in conservative variety: MAX- $\mu \gg *$ FINALLONGV

\begin{tabular}{|l||c|c|c|}
\hline \multicolumn{1}{|c|}{$\operatorname{di}:$} & MAX- $\mu$ & $* \mu$ & $*$ FINALLONGV \\
\hline \hline a. ${ }^{\prime}{ }^{\prime} \operatorname{di}_{\mu \mu}$ & & $* *$ & $*$ \\
\hline b. $\quad \operatorname{dil}_{\mu}$ & $* !$ & $*$ & \\
\hline
\end{tabular}

b. No lengthening in conservative variety: *FINALLONGV $\gg$ FOOT BINARITY

\begin{tabular}{|c||c|c|}
\hline di & *FINALLONGV & FTBIN \\
\hline \hline a. $\quad \operatorname{di}_{\mu \mu}$ & $* !$ & \\
\hline b. ${ }^{\prime}$ ' $^{\prime} \mathrm{di}_{\mu}$ & & $*$ \\
\hline
\end{tabular}

Innovative varieties which neutralize the length contrast in word-final stressed syllables are accounted for with a ranking of *FINALLONGV above MAX- $\mu$, which ensures shortening of stressed vowels in this position. The constraint *FINALLONGV is admittedly a restatement of the facts rather than an explanation. However, this constraint (or set of constraint rankings having this effect) is not unprecedented typologically: for instance, stress fails to compel lengthening of word-final vowels in (some varieties of) Standard Italian (D'Imperio and Rosenthall, 1999; Krämer, 2009). Similarly, in many languages iambic lengthening is blocked wordfinally, e. g. in Kashaya (Buckley, 1992); see further Hayes (1995), who calls this blocking "mysterious" (p. 269). For reasons of space and focus I do not discuss the nature of this constraint further. However, it is clear that the requirement (however formalized) to avoid word-final long vowels plays an important rôle in the (non-) realization of underlying length contrasts, cf. Loporcaro (2011b): "the choice between application [...] vs. non-application [...] of lengthening in word-final stressed syllables is $[\ldots]$ a purely phonological one". ${ }^{11}$

\footnotetext{
${ }^{11}$ The length contrast is also neutralized in antepenultima, again in favour of the short vowel. While these data are not directly relevant to the subject of this paper, they also demand an explanation. A full account of Friulian metrical structure is far beyond the scope of this paper. Tentatively, however, one might suggest that long vowels in penultima shorten because length is only licensed under main stress (e.g. due to a combination of a ban on monosyllabic feet dominated by MAINTO-WEIGHT, for which see Bye and de Lacy, 2008). If the Friulian foot is a moraic trochee (which is consistent with the data considered in this paper), words ending in an input ... HLL (which are certainly provided by the rich base) are expected to receive the parse ...(H)(LL); if we further assume that main stress always falls on the rightmost foot, the length in the antepenultimate syllable would then remain unlicensed. Thus, the candidate with the long vowel would be defeated by one
} 


\subsubsection{Sonorant weight}

The simplest system in Friulian is seen before laterals. Recall that long vowels in Friulian contrast with short vowels before the segment [1], as the minimal pair in (23) demonstrates.
a. ['val]
b. ['va:l]
'valley'
'(it) costs'

The difference between the moraic structure of the two forms cannot be due to differences in their phonological make-up, since their segmental forms are identical.

I propose that the contrast in the case of laterals is one of underlying consonant weight. This means that a faithfulness-over-markedness ranking is in operation. The relevant faithfulness constraint is $\operatorname{MAXLINK}(\mu)[$ lat], which has to outrank at least EXTRAmETRICALITY, $* \mu[$ lat] and $* \mu$ [cons]. The first of these militates against word-final moraic consonants, the second penalizes moraic segments associated with a [lateral] feature, and the last one assigns a violation mark for each moraic segment specified as a consonant. ${ }^{12}$ This is shown in (24) for underlyingly moraic laterals, which surface with a short vowel. ${ }^{13}$ Here, as in all tableaux throughout this paper, I omit the rankings which ensure that vowels (i. e. syllable nuclei) have at least one mora.

with a short vowel allowing for a ... (ĹL)L parse (or even ... L(ĹL) if faithfulness does not compel stress on the antepenult).

${ }^{12}$ Here, I use [cons] as a general placeholder for whatever features all consonants in the language have.

${ }^{13}$ I assume that words such as ['val] indeed have a moraic coda and are not monomoraic. I treat this as a potentially testable empirical prediction. According to Baroni and Vanelli (2000), word-final voiceless obstruents (which I treat as moraic, see below) are phonetically longer than devoiced obstruents (which I treat as nonmoraic), and therefore it appears that moraic codas are indeed phonetically longer in Friulian. Thus, the prediction is that the lateral in ['val] could be a longer segment than the lateral in ['va:l]. 


\begin{tabular}{|c|c|c|c|c|}
\hline $\operatorname{val}_{\mu}$ & $\operatorname{MAXLINK}(\mu)[$ lat $]$ & EXTRAMETRICALITY & $* \mu$ [lat $]$ & $* \mu[\mathrm{cons}]$ \\
\hline a. $\mathrm{va}_{\mu} \mathrm{l}_{\mu}$ & & $*$ & $*$ & * \\
\hline b. $\quad$ va: $\mu \mu 1$ & $* !$ & & & $\begin{array}{l}1 \\
1\end{array}$ \\
\hline c. $\quad \mathrm{va}_{\mu} 1$ & *! & & & i \\
\hline
\end{tabular}

As for long vowels in monosyllables before a lateral, I propose that these derive from underlyingly short vowels. This is confirmed by alternations found in pairs of forms such as ['sa:l] 'salt' vs. ['sale] '(s)he costs'. I analyze the lengthening as stemming from a binarity requirement, which rules out monomoraic candidates. Given a choice between two bimoraic candidates, the computation selects the candidate with both morae associated to the vowel. In theory, this can be due either to EXTRAMETRICALITY or to a moraic markedness constraint (* $\mu$ [lat] or $* \mu$ [cons]). I suggest that the correct answer here is EXTRAMETRICALITY, for reasons discussed immediately below. This constraint must dominate the constraint encouraging moraicity of the consonant, i. e. WeIGHT BY POSITION. At this point a single WEIGHT BY POSITION constraint appears sufficient to derive the facts.

EXTRAMETRICALITY $\gg$ WEIGHT BY POSITION
\begin{tabular}{|c|c|c|}
\hline \multicolumn{1}{|c|}{ val } & EXTRAMETRICALITY & WBP \\
\hline \hline a. $\operatorname{va}_{\mu \mu} 1$ & & $*$ \\
\hline b. $\quad \operatorname{va}_{\mu} 1$ & & $*$ \\
\hline c. $\quad \operatorname{va}_{\mu} 1_{\mu}$ & $* !$ & \\
\hline
\end{tabular}

The ranking of foot binarity here is indeterminate, as it only contributes to harmonic bounding of candidate (25-b).

Clues as to why it is extrametricality and not moraic markedness that plays the decisive rôle are found in the behaviour of liquids in clusters. Specifically, if the coda [1] is not word-final, the vowel length contrast is neutralized: while ['alt] 'high' is a possible form, *['a:lt] is not. I assume this means that a non-final [1] in a cluster is always moraic, and vowel lengthening is not necessary to achieve binarity. In other words, WEIGHT BY POSITION must outrank (at least) $* \mu$ [lat] and $* \mu$ [cons]. This is a classic emergence of the unmarked ranking made possible by the inactivity of EXTRAMETRICALITY in the cluster context. The ranking is 
shown in (26) using ['cald] 'warm (masc.)' (orthographically cjalt, but cf. feminine ['calde]) as an example. ${ }^{14}$ This ranking shows that moraic markedness cannot be the constraint preventing consonant moraicity in (25), since this would imply a ranking conflict.

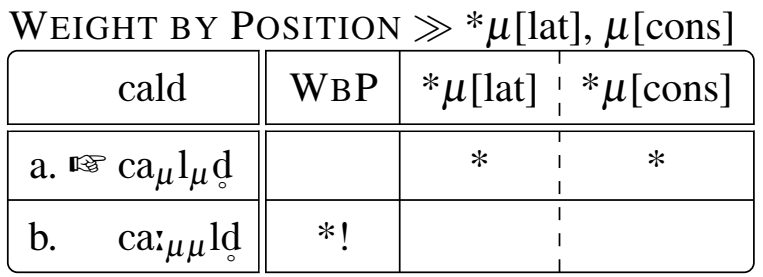

The ranking established so far for the laterals does not have issues with Richness of the Base. Candidates with an input long vowel and a single lateral in the coda (a hypothetical $/ \mathrm{va}_{\mu \mu} \mathrm{l} /$ ) are unproblematic, because the fully faithful candidate does not violate any of the constraints set up so far. Inputs with three morae (of the type ['va: $\mu \mu 1_{\mu}$ ]) cannot surface faithfully by a highly ranked $* \mu \mu \mu$ (unviolated in the language), as we shall see below. I defer discussion of potential inputs with a long vowel before lateral-obstruent clusters until later.

The two other sonorant types (nasals and rhotics) behave differently from laterals, in that there is no contrast in vowel length before either of them. Such lack of contrast is a hallmark of a coerced rather than distinctive weight system, and coerced weight is due to a high ranking of markedness. In the remainder of this section I explore the nature of the relevant markedness constraints, and show that a fixed sonority-based hierarchy of moraic markedness constraints does not make correct empirical predictions.

We start with moraicity of nasals. Vowels are always short before coda nasals. This is an example of coerced weight: WEIGHT BY POSITION has to outrank all faithfulness and most markedness constraints, making sure - in concert with the constraint against trimoraic syllables - that even input long vowels shorten. The dominated constraints are at least $* \mu$ [cons], $* \mu$ [nas] and EXTRAMETRICALITY. This is shown in (27) for [man] 'hand'.

\footnotetext{
${ }^{14}$ The representation of the final obstruent is immaterial at this point. See section 3.3.3 for discussion of final obstruents and section 3.4.3 for their behaviour in clusters.
} 


\begin{tabular}{|c||c|c:c:c|}
\hline \multicolumn{1}{|c|}{$\operatorname{may}$} & WBP & $* \mu[$ cons] & $* \mu[$ nas] & EXTRAMETRICALITY \\
\hline \hline a. $\operatorname{ma}_{\mu} \mathrm{y}_{\mu}$ & & $*$ & $*$ & $*$ \\
\hline b. $\quad \max _{\mu \mu} \mathrm{y}$ & $* !$ & & & \\
\hline
\end{tabular}

The same ranking extends straightforwardly to clusters, as in ['camp] 'field'. For long vowels provided by the rich base to shorten, WEIGHT BY POSITION and the constraint against trimoraic syllables have to dominate faithfulness, as seen in (28).

\begin{tabular}{|c|c|c|c|}
\hline $\mathrm{ma}_{\mu \mu} \mathrm{y}$ & $* \mu \mu \mu$ & WвP & MAXLINK $-\mu[\mathrm{V}]$ \\
\hline a. $\mathrm{ma}_{\mu} \mathrm{y}_{\mu}$ & & & $*$ \\
\hline b. $\quad \operatorname{ma}_{\mu \mu} \mathrm{y}$ & & $* !$ & \\
\hline c. $\mathrm{ma}_{\mu} \mathrm{y}$ & & $* !$ & $*$ \\
\hline d. $\quad \operatorname{ma}_{\mu \mu} \mathrm{y}_{\mu}$ & $* !$ & & \\
\hline
\end{tabular}

So far, the system is unremarkable. However, coda rhotics provide an interesting twist. These segments present another instance of coerced weight. As discussed above in connection with the realization of word-final nonmoraic [1], vowel lengthening can be due to at least one of $* \mu$ [rhotic] or EXTRAMETRICALITY dominating WEIGHT BY POSITION. This is shown in (29) (I use the lack of a line in the tableau to show disjunction).

$* \mu$ [rhotic $] \vee$ EXTRAMETRICALITY $\gg$ WEIGHT BY POSITION
\begin{tabular}{|c||cc|c|}
\hline car & $* \mu$ [rhotic] & EXTRAMETRICALITY & WBP \\
\hline \hline a. $\mathrm{ca}_{\mu \mu} \mathrm{r}$ & & $*$ \\
\hline b. $\quad \mathrm{ca}_{\mu} \mathrm{r}_{\mu}$ & $* ?$ & $* ?$ & \\
\hline
\end{tabular}

Juxtaposing this ranking with the one established in (27) reveals not one, but two problems with our assumptions so far: it turns out that both rankings are incompatible with the version of the standard theory that we have been using.

The ranking of EXTRAMETRICALITY above WEIGHT BY POSITION is directly incompatible with the ranking needed to derive the facts for the laterals, 
meaning both rankings cannot be part of the same language. However, the ranking of $* \mu$ [rhotic] over WeIGHT BY POSITION is not feasible under the standard theory either: this is because given the rankings in (29) and (27), ${ }^{*} \mu$ [rhotic] must, by transitivity, dominate $* \mu$ [nasal]. This cannot be the case in the standard theory, where more sonorous segments are universally preferred moraic codas, and liquids are normally acknowledged to be more sonorous than nasals.

Thus, both options needed to derive the correct result in (29) seem to necessitate some adjustments to the theory, which I will discuss shortly. Even more interestingly, both options appear to be attested, possibly in different varieties of Friulian. The exact ranking hinges on the behaviour of the rhotic in clusters. If $[\mathrm{r}]$ is like [1] — vowel lengthening before underlyingly nonmoraic rhotics is due to extrametricality, meaning that WEIGHT BY POSITION outranks moraic markedness - the prediction is that vowels before [r]-obstruent clusters should be uniformly short, via the same mechanism as that shown in (26); if, on the other hand, moraic $[\mathrm{r}]$ is absolutely impossible in the language, $* \mu$ [rhotic] should outrank WEIGHT BY POSITION, as shown in (30); again, we defer discussion of the moraicity of the obstruent until later. The latter ranking is shown in (30)

\begin{tabular}{|c|c|c|}
\hline spork & $* \mu[$ rhotic $]$ & WBP \\
\hline a. $\operatorname{spo:~} \mu \mu \mathrm{rk}$ & & $*$ \\
\hline b. $\quad \operatorname{sp}_{\mu} \mathrm{r}_{\mu} \mathrm{k}$ & $* !$ & \\
\hline
\end{tabular}

In fact, as we have seen in section 1.2, this particular context is subject to variation: Baroni and Vanelli (2000) claim that vowels lengthen before such clusters, while Finco (2009) describes the vowel as phonologically short. Presumably this is a matter of different rankings in different varieties; therefore, whatever amendments to the standard theory are needed to resolve the ranking conflicts, both appear necessary to derive the correct range of variation. ${ }^{15}$

\footnotetext{
${ }^{15}$ An anonymous reviewer asks if the typologically unusual dispreference for moraic rhotics might be related to their phonetic realization, and suggests that the issues could be settled by more careful instrumental study. I agree that such a study would be valuable, but must leave this question aside. Existing sources (Miotti, 2002; Finco, 2009) are in general agreement that the rhotic is an alveolar tap in all positions, though trilled realizations and velarized taps are not impossible. That the variation between long and short vowels before $[\mathrm{rC}]$ is real and possibly dialectally driven appears confirmed by Finco (2007). He compares the duration of vowels before word-final [rC]
} 
Finally, we have to assume that both $* \mu \mu \mu$ and at least one of EXTRAMETRICALITY and $* \mu$ [rhotic] (depending on dialect) outrank MAXLink $(\mu)[$ rhotic], to make sure that moraic [r] provided by the rich base does not surface as such.

The amendments to standard theory I propose are as follows. First, as noted in section 3.3 I suggest that WEIGHT BY POSITION constraints need to be relativized to the featural content of the relevant segments. If the weight-by-position constraints in (26), (27) and (29) are in fact different constraints, as shown below, the conflict disappears, and the rankings are reconcilable. The amended rankings are shown in (31).

a. Weight By Position[lat] $\gg * \mu[$ lat $], \mu[$ cons $]$

\begin{tabular}{|c||c|c|c|}
\hline \multicolumn{1}{|c|}{ cald } & WBP[lat] & $* \mu[$ lat $]$ & $* \mu$ [cons] \\
\hline \hline a. ca $_{\mu} 1_{\mu}$ d & & $*$ & $*$ \\
\hline b. $\quad$ ca $_{\mu \mu}$ ld & $* !$ & & \\
\hline
\end{tabular}

b. $\mathrm{WBP}[\mathrm{nas}] \gg * \mu[\mathrm{cons}], * \mu[\mathrm{nas}]$, EXTRAMETRICALITY

\begin{tabular}{|c||c|c:c:c|}
\hline \multicolumn{1}{|c|}{$\operatorname{may}$} & WBP[nas] & $* \mu[$ cons] & $* \mu[$ nas] & EXTRAMETRICALITY \\
\hline \hline a. $\operatorname{ma}_{\mu} \mathrm{y}_{\mu}$ & & $*$ & $*$ & $*$ \\
\hline b. $\operatorname{ma}_{\mu \mu} \mathrm{y}$ & $* !$ & & & \\
\hline
\end{tabular}

c. $* \mu$ [rhotic] $\vee$ EXTRAMETRICALITY $\gg$ WEIGHT B Y POSITION[rhotic]

\begin{tabular}{|c|cc|c|}
\hline car & $* \mu$ [rhotic] & EXTRAMETRICALITY & WBP[rhotic] \\
\hline \hline a. $\mathrm{ca}_{\mu \mu} \mathrm{r}$ & & & $*$ \\
\hline b. $\quad \mathrm{ca}_{\mu} \mathrm{r} \mu$ & $* ?$ & $* ?$ & \\
\hline
\end{tabular}

If the WeGHT B P POSITION constraints are relativized, the issue with violating the universal hierarchy also disappears. Specifically, if moraic markedness

and $[\mathrm{IC}]$ sequences and finds that they are longer before $[\mathrm{rC}]$ than before $[\mathrm{lC}]$ in Central Friulian varieties (San Daniele and Tarcento), but that the situation is reversed in the so-called Carnic dialects, spoken in the north-west of the Friulian area (represented in his data by the varieties of Preone and Pradumbli). These data are not in any way conclusive, and further study is certainly warranted. The reviewer also asks whether instrumental study of laterals has been conducted. I am not aware of any such studies. Finco (2007) does show that the vowel length contrast obtains before [1] in all varieties, and at least in his Central dialects the duration of the vowel before wordfinal $[1 \mathrm{C}]$ is relatively short (in any case it is shorter than a long vowel before [1]). Again, this calls for more detailed study. 
constraints are only ranked with respect to the corresponding weight-by-position constraints, there is no transitivity-based argument for their relative ranking. In any case, in the presence of the relativized weight by position constraints the moraic markedness hierarchy as such is inert: all moraic markedness constraints operating on consonants - i. e. both the general $* \mu$ [cons] and the more mannerspecific ones such as $* \mu[$ lat $]$ - occupy the same stratum on the hierarchy, cf. the overall ranking presented in figure 1 on page 36 . However, before we turn to the complete ranking, an account of obstruent weight is also necessary. This account is the subject of the next section.

\subsubsection{Obstruent weight}

Recall that in section 3.2 I proposed there is no final laryngeal neutralization in Friulian. Rather, the language exhibits markedness reduction, from which voiceless obstruents are protected. It is due to the ranking *ALIGN-R(Wd,Lar) $\gg$ MAX(Lar), as shown in (32). I also show the featural specifications assumed for the word-final segment for ease of exposition. ${ }^{16}$

\begin{tabular}{|c|c|c|c|}
\hline lad & $\langle$ Root,Lar $\rangle$ & *ALIGN-R(Wd,Lar) & MAX(Lar) \\
\hline a. $\operatorname{la}_{\mu \mu} \mathrm{d}$ & $\langle\operatorname{Root}\rangle$ & & $\langle$ Lar $\rangle$ \\
\hline b. $\quad \operatorname{la}_{\mu} \mathrm{d}$ & $\langle$ Root,Lar $\rangle$ & $* !$ & \\
\hline c. $\quad \operatorname{la}_{\mu} \mathrm{d}_{\mu}$ & $\langle$ Root,Lar $\rangle$ & $* !$ & \\
\hline d. $\quad \operatorname{la}_{\mu \mu} \mathrm{d}$ & $\langle$ Root,Lar $\rangle$ & *! & \\
\hline
\end{tabular}

Word-final voiceless obstruents, on the other hand, resist this process. That is, the imperative to delete Lar specifications in word-final positions established by the ranking in (32) cannot be fulfilled because $\operatorname{MAX}([\mathrm{vcl}])$ dominates the disalignment constraint, and by our representational assumptions, all segments containing [ $\mathrm{vcl}]$ also contain the Lar node. This is exactly the mechanism establishing de Lacy's (2006) Preservation of Marked: a markedness constraint may dominate a faithfulness constraint targeting a bigger class of structures, but some subset of those structures is protected by a more specific faithfulness constraint. This is demonstrated in (33).

\footnotetext{
${ }^{16}$ For reasons of focus I do not discuss the well-known issues with the too-many-solutions problem arising from this approach to final devoicing (Lombardi, 2001).
} 


\begin{tabular}{|c|c|c|c|c|}
\hline lat & $\langle$ Root,Lar,[vcl] $\rangle$ & $\operatorname{MAx}([\mathrm{vcl}])$ & *ALIGN-R(Wd,Lar) & MAX(Lar) \\
\hline a. $\mathrm{la}_{\mu} \mathrm{t}_{\mu}$ & $\langle$ Root,Lar,[vcl] $\rangle$ & & $\langle$ Lar $\rangle$ & \\
\hline b. $\quad \operatorname{la}_{\mu} \mathrm{d}_{\circ}$ & $\langle$ Root $\rangle$ & [vcl]! & & $\langle$ Lar $\rangle$ \\
\hline c. $\quad \operatorname{la}_{\mu \mu} \mathrm{d}$ & $\langle$ Root $\rangle$ & [vcl]! & & $\langle$ Lar $\rangle$ \\
\hline d. $\quad \operatorname{la}_{\mu} \mathrm{d}_{\mu}$ & $\langle$ Root,Lar $\rangle$ & {$[\mathrm{vcl}] !$} & $\langle$ Lar $\rangle$ & \\
\hline e. $\quad$ la: $\mu \mu \mathrm{d}$ & $\langle$ Root,Lar $\rangle$ & [vcl]! & $\langle$ Lar $\rangle$ & \\
\hline
\end{tabular}

Having established the rankings required to derive these laryngeal specifications, we are in a position to account for the weight facts. In the case of inputs with a voiceless obstruent, no vowel lengthening obtains because the final obstruent projects a mora. Its moraicity is the product of the constraint WEIGHT BY POSITION(Lar), parallel to other relativized WEIGHT BY POSITION constraints. ${ }^{17}$ It must dominate EXTRAMETRICALITY, $\mu$ [cons] and the general anti-moraicity constraint $* \mu{ }^{18}$

\begin{tabular}{|c|c|c|c|c|}
\hline lat & WвP(Lar) & EXTRAMETRICALITY & $* \mu[\mathrm{cons}]$ & $* \mu$ \\
\hline a. $\quad \mathrm{la}_{\mu} \mathrm{t}$ & $* !$ & & & * \\
\hline b. $\mathrm{la}_{\mu} \mathrm{t}_{\mu}$ & & * & $*$ & $* *$ \\
\hline c. $\quad l \mathrm{a}_{\mu \mu} \mathrm{t}$ & $* !$ & & & $* *$ \\
\hline
\end{tabular}

As for candidates with an underlying voiced obstruent (which surfaces as a delaryngealized segment), the fact that vowel lengthening happens at all demonstrates that FOOT BINARITY dominates the general anti-moraicity constraint; the precise ranking of $* \mu$ [cons] with respect to these constraints cannot be estab-

\footnotetext{
${ }^{17}$ Alternatively, it could have been Weight By Position([voiceless]). I adopt the WeIGHT BY POSITION(Lar) constraint as being the more general one, since it targets (contrastively specified) obstruents and not just voiceless ones.

${ }^{18}$ The ranking of WEIGHT B P POSITION(Lar) over * $\mu$ is not strictly speaking necessary, since candidate (a.) in (34) is also defeated by FoOt BinARITY. Still, this ranking does not lead to incorrect results.
} 
lished, but it contributes to vowel lengthening in that it excludes the candidate with a moraic coda.

\begin{tabular}{|c|c|c|c|}
\hline lad & FTBIN & $* \mu$ & $\mu[$ cons $]$ \\
\hline a. $\Leftrightarrow \mathrm{la}_{\mu \mu} \mathrm{d}$ & & $* *$ & \\
\hline b. $\quad \operatorname{la}_{\mu} \mathrm{d}_{\mu}$ & & $* * \backslash$ & $* !$ \\
\hline c. $\quad l \mathrm{a}_{\mu} \mathrm{d}$ & $* !$ & $*$ & \\
\hline
\end{tabular}

Finally, in the case of non-oxytonic stress binarity requirements compel the creation of a bisyllabic foot rather than the projection of a mora from the coda of the stressed syllable. There can be several explanations for this. For the sake of the argument, I assume that these facts are due to the same ranking as the one in (35). The derivation is shown in (36); constraints which conspire to ensure that every vowel projects at least one mora, and those responsible for stress placement, are excluded for reasons of focus. ${ }^{19}$

\begin{tabular}{|c|c|c|c|}
\hline 'lade & FTBIN & $* \mu$ & $\| * \mu[\mathrm{cons}]$ \\
\hline a. ${ }^{\prime} \mathrm{la}_{\mu} \mathrm{de}_{\mu}$ & & $* *$ & 《 \\
\hline b. $\quad l a_{\mu} \mathrm{de}$ & $* !$ & $*$ & $\mathbb{Z}$ \\
\hline c. $\quad{ }^{\prime} \mathrm{a}_{\mu} \mathrm{d}_{\mu} \mathrm{e}$ & & $* *$ & $* !$ \\
\hline d. $\quad{ }^{\prime} \mathrm{la}_{\mu \mu} \mathrm{de}_{\mu}$ & & $* * * !$ & 》 \\
\hline
\end{tabular}

The above account represents a coerced-weight (sub)system in terms of Morén (2001). A relevant issue is Richness of the Base. Specifically, as it stands, the system does not allow moraic obstruents other than voiceless ones. The rich base contains inputs such as $/ \operatorname{lad}_{\mu} /$ and $/ \operatorname{lad}_{\mu} /$, which under the present proposal are impossible surface forms. The question then is what excludes the fully faithful candidates for these inputs: it cannot be any part of the mechanism pro-

\footnotetext{
${ }^{19}$ The winning candidate has a final mora, which would seem to violate EXTRAMETRICALITY, but I assume that the latter is inoperative, either because the constraint is formulated in terms of final-consonant extrametricality (Vaux and Wolfe, 2009), or because some ranking is in force which makes sure that all vowels are moraic despite EXTRAMETRICALITY.
} 
posed above, since the ranking established so far can only ensure that morae are not added to Lar-less segments by the computation, but says nothing about input morae. An obvious solution involves a markedness-over-faithfulness ranking which ensures that input morae never play a rôle, in other words $\mu$ [cons] outranks MAXLINK- $\mu$ [cons]. This ensures that consonantal morae in the input will not surface faithfully (unless a third factor intrudes, as presumably in the case of the input $/ l^{1} t_{\mu} /$, which is a licit output representation modulo vowel moraicity). The constraint $* \mu$ [cons] also has to outrank WEIGHT BY POSITION[cons], as shown in (37).

$* \mu[$ cons] $\gg$ MAXLINK- $\mu$ [cons], WEIGHT BY POSITION[cons]
\begin{tabular}{|c||c|c|c|}
\hline $\operatorname{lad}_{\mu}$ & $* \mu[$ cons] & MAXLINK $-\mu$ [cons] & WBP[cons] \\
\hline \hline a. la: $_{\mu \mu} \mathrm{d}$ & & $*$ & $*$ \\
\hline b. $\quad \operatorname{la}_{\mu} \mathrm{d}_{\mu}$ & $* !$ & & \\
\hline
\end{tabular}

Finally, we consider inputs with long vowels provided by the rich base. Inputs of the type /laid/ present no significant problems, since the candidate with final delaryngealization but no change in moraic structure is a licit output, i. e. [la:d]. As for inputs with a long vowel and a voiceless consonant, the outcome is difficult to know, since most sources are silent on whether a long vowel before a voiceless obstruent is legitimate in Friulian. However, Morin (2003) draws attention to the existence of the long vowel [o:] before voiceless obstruents when the vowel is derived from *AU. He only cites two examples, but at least one of them shows that underlyingly the consonant is indeed voiceless: ['o:k] 'gander', ['o(:)ce] 'goose',20 there is also ['po:k] 'few' (also confirmed by Frau, 1984, p. 108 for Udinese Friulian), and at least the orthography suggests the $[\mathrm{k}]$ is voiceless (feminine plural pocjis).

The problem for the analysis here is that these sources do not distinguish between voiceless and devoiced obstruents. The forms ['ork] and ['po:k] are exceptional, but it is not clear how exactly. If their final obstruents are voiceless, one possible analysis is as follows. The final consonant is nonmoraic, since the constraint against trimoraic syllables dominates MAXLINK- $\mu[\mathrm{V}]$ (tableau (28)), and MAXLinK- $\mu[\mathrm{V}]$ dominates Weight By Position(Lar), as shown in (38).

\footnotetext{
${ }^{20}$ The long vowel in ['o:ce] also confirms the underlying status of length in these morphemes.
} 


MAXLINK- $\mu[\mathrm{V}] \gg$ WEIGHT BY POSITION(Lar)
\begin{tabular}{|lc||c|c|c|}
\hline & $\operatorname{po}_{\mu \mu} \mathrm{k}$ & $* \mu \mu \mu$ & MAXLINK- $\mu[\mathrm{V}]$ & WBP(Lar) \\
\hline \hline a. $\quad \operatorname{po}_{\mu} \mathrm{k}_{\mu}$ & & $* !$ & \\
\hline b. $\operatorname{po:}_{\mu \mu} \mathrm{k}$ & & & $*$ \\
\hline c. $\quad \operatorname{po:}_{\mu \mu} \mathrm{k}_{\mu}$ & $* !$ & & \\
\hline
\end{tabular}

A potential problem with this ranking is that it predicts that faithfulness to underlyingly long vowels can force violations of WEIGHT B Y POSITION(Lar), with the result that underlyingly long vowels should not shorten before obstruent clusters, which, at face value, seems incorrect. However, I believe there is some evidence that this is in fact a correct prediction; see the discussion below in section 3.4.2. ${ }^{21}$

This concludes the OT analysis of the core ideas presented in section 3.1; in the next section I turn to some remaining outstanding issues.

\subsection{Residual issues}

In this subsection I consider some residual cases, namely those of clusters, of the postalveolar affricate, and of exceptional lengthening before [ $[\mathrm{t}]$.

\subsubsection{Obstruent clusters and postalveolars}

Stressed vowels are almost uniformly short before final obstruent clusters. The lack of lengthening before such clusters follows straightforwardly from the system presented above, and more specifically from the nature of the disalignment constraint *ALIGN-R(Lar,Wd). Given the logic of minimal violation, this constraint will ensure that the number of segments losing their laryngeal specification will be just enough to satisfy the constraint, namely one. A consequence of this is that the first obstruent in a cluster will retain its laryngeal specification and will be subject to weight-by-position.

This point is somewhat difficult to illustrate, since most if not all obstruentobstruent clusters in Friulian are voiceless (as in ['gust] 'taste', cf. [gus'ta] 'to have lunch'), and are in any case expected to retain this laryngeal specification. The

\footnotetext{
${ }^{21}$ Alternative solutions are available. For instance, one could suggest that the voiceless obstruents in pocjis and ocje are derived, i. e. that the roots in these words are underlyingly /po:g/ and /o:g/, and that they are morphologically unusual in taking an additional suffix consisting of the floating feature [voiceless]. In this case, the long vowel in the singular is completely unproblematic, with a surface form of the ['la:d] type.
} 
derivation for a hypothetical input /guzd/ (provided by the rich base) is shown in (39). The constraint $\operatorname{MAX}(\mathrm{Lar})$ has to dominate $* \mu$ [cons], since otherwise we could expect delaryngealization as strategy to repair consonant moraicity.

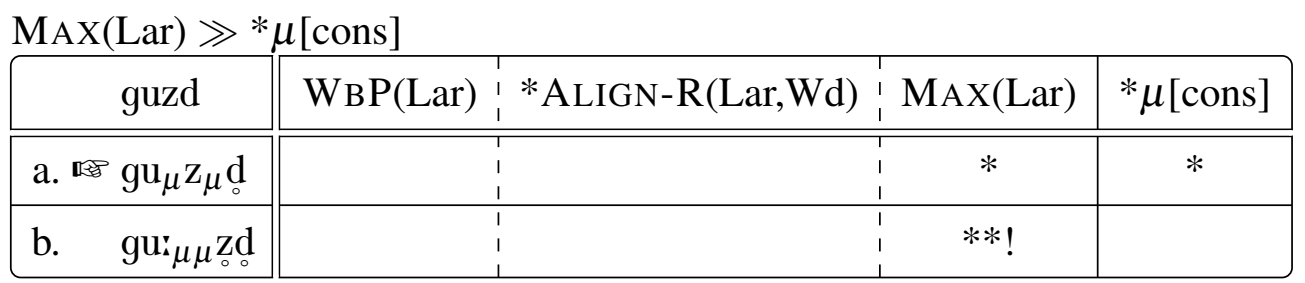

The point of the tableau in (39) is to demonstrate that delaryngealizing the entire obstruent cluster (and thus lengthening the vowel) does not represent a harmonic improvement. Since I have not been able to find an input of the relevant form, it is difficult to judge to what extent the form in (39-a) is a possible winner in Friulian, and how it can be implemented phonetically. Nevertheless, it demonstrates a prediction of the system argued for in the present paper, which is relevant for the behaviour of the postalveolar affricates [ $[\mathrm{t}]$ and [dz]. These are different from other obstruents, because they cannot be preceded by long vowels, as in ['mjetf] 'half' (cf. feminine ['mjedze]). This is a problem if, as commonly assumed, affricates represent unitary segments patterning with stops (cf. Rubach, 1994 for Polish or Morén, 2006 for Serbian).

However, it is worth recalling that Friulian has a typologically unusual contrast between postalveolar affricates $([\widehat{\mathrm{t}} \widehat{\widehat{\mathrm{d}}} \mathrm{3}]$ ) and palatal stops $([\mathrm{c} \mathrm{f}])$, which means that the affricates cannot be palatal stops phonologically. I propose that they are represented in the phonology as clusters of two root nodes, and thus should not behave in the manner of unitary stops. Thus, an input like $/$ mjed $\widehat{3} /$ is submitted to the ranking sketched in (39), and the surface-phonological representation of [mjet]] is in fact something like [mjed3], with a moraic stop, as shown in that tableau. This prediction is not trivial from a phonetic perspective, since it assumes that the stop part of the affricate is phonologically voiced. Given, however, that the cluster is phonetically an affricate, i. e. with a short plosive component, it is not immediately obvious that this prediction is incorrect; instrumental study would be necessary. $^{22}$

\footnotetext{
${ }^{22}$ Alternatively, a more nuanced representation of affricates (e. g. with recursive root nodes) can make sure that the voiced component is not visible to the phonetics-phonology interface. Again, the answer hinges on several issues which I cannot take up here.
} 
The account proposed here underlines the single motivation for the exclusion of vowel length from pre-cluster and pre-affricate position, and it formally expresses the intuition of Baroni and Vanelli (2000), who state that "affricates... are longer "by nature"' (p. 19), but do not provide a formal account. Note that the present approach is incompatible with accounts of final devoicing that rely on across-the-board bans against laryngeal features suspended in certain prosodic positions (Bethin, 1992; Beckman, 1998) or before vowels or sonorants (Lombardi, 1995a; Rubach, 2008; Beckman et al., 2009). This is because such accounts predict that all obstruents between the nucleus and the syllable boundary should undergo delaryngealization (as in candidate (b.) in (39)), and this leads to incorrect predictions for Friulian.

I do not provide an account of the facts related to the plural suffix /-s/ (see example (6-b-ii) on p. 6). Recall that a long vowel is permitted in cases such as ['lu:ks] 'places', from [lu:g], yet there is a strong tendency for cluster reduction in this context. Without more reliable data on this cluster reduction, no accurate account is possible. Where the supposedly illegal long vowel before a cluster does surface, it is probably a cyclic effect, and will have to analysed in the same way as other instances of cyclic overapplication.

\subsubsection{Morphological lengthening}

As discussed in section 3.3.3, the account of obstruent weight adopted in this paper has a drawback in that it predicts that underlying vowel length should trump obstruent moraicity. Thus, while the ranking shown in (39) ensures that short vowels are not lengthened before obstruent clusters, an underlying long vowel should surface faithfully at the cost of a nonmoraic Lar obstruent.

I suggest that this is exactly the correct prediction, if we assume that postalveolar affricates are also consonant clusters. As noted in section 1.2, in some morphological forms, long vowels are possible before postalveolar affricates, for instance in [dis'truitf] '(s)he destroys'. Given that the process is morphologically conditioned, we can assume that the extra mora on the vowel is an exponent of the relevant morphological category, meaning that this is exactly the situation where the phonology receives a long vowel before a cluster as input. Under the ranking established in section 3.3.3, the vowel remains long, which is empirically correct. 


\begin{tabular}{|c|c|c|c|}
\hline $\operatorname{distru}_{\mu \mu} \mathrm{d} 3$ & $* \mu \mu \mu$ & MAXLINK- $\mu[\mathrm{V}]$ & WвP(Lar) \\
\hline a. distru: $\mu \mu \mathrm{d}_{3}$ & & & * \\
\hline b. distru: $\mu \mu \mathrm{d}_{\mu 3}$ & *! & & \\
\hline c. $\quad \operatorname{distru}_{\mu} \mathrm{d}_{\mu 3}$ & & $* !$ & \\
\hline
\end{tabular}

Note that this result is achieved without any reference to morphology in the phonological computation.

\subsubsection{Sonorant-obstruent clusters}

In the discussion of sonorant weight in section 3.3.2, I focused on the moraic status of the sonorant immediately following the nucleus to derive the length of the vowel in words such as ['cald] 'warm' or ['sporrk] 'dirty'. Empirically, the underlying laryngeal specification of the final obstruent in a cluster does not influence the length of the vowel: for instance, the vowel is short both in ['cald] 'warm' (feminine ['calde]) and in [alt] (feminine [alte]). This turns out to be an issue under a naïve interpretation of the analysis.

The standard analysis of this sort of insensitivity to the final segment involves final-consonant extrametricality (e.g. Vaux and Wolfe, 2009). However, this is precisely the device that is not available in Friulian, since extrametricality can be defeated by the combined effect of $\mathrm{MAX}([\mathrm{vcl}])$ and $\mathrm{WBP}(\mathrm{Lar})$. The ranking established for the vowel length facts (cf. figure 1 on page 36) predicts that final voiceless obstruents should be moraic also in clusters. This is especially problematic for cases such as [spork] 'dirty' (cf. fem. sg. sporcje), since under the assumption of final-obstruent moraicity these seem to be trimoraic, and I have argued that trimoraic syllables are impossible in Friulian. Moreover, it is predicted that inputs like /cald/ (with an underlyingly non-moraic [1] and a voiced obstruent) should be indistinguishable from inputs like /val/, and therefore surface with a long vowel, which is incorrect.

I suggest that the solution to this conundrum is representational. If final segments were to be moraic, the moraic parse of the segment sequence would have to be discontinuous, as in [spo: $\left.\mu \mu \mathrm{rk}_{\mu}\right]$, in violation of some locality condition. Specifically, I assume that such trapped segments essentially cannot be prosodically parsed: while peripheral non-moraic segments can be rescued by adjunction to a higher prosodic constituent such as the prosodic word (e.g. Vaux and Wolfe, 2009), trapped segments cannot be parsed in this manner, because such adjunction 
would involve a violation of standard requirements with respect to the linearization of arboreal structure. I assume, therefore, that candidates such as [spo: ${ }_{\mu \mu} \mathrm{rk}_{\mu}$ ] are either not submitted to EVAL at all ${ }^{23}$ or excluded by constraints regulating the prosodic parse (for instance, van Oostendorp, 2000, p. 97 recruits the CONTIGUITY constraint to similar effect). Another option is assuming a ban on complex codas and treating the final consonant as the head of a degenerate syllable (Aoun, 1979), a solution in fact proposed for Friulian by Repetti (1994), though in a different context, see below in section 4.1. A full exploration of these issues is far beyond the scope of this paper, but for the present purposes it is sufficient to conclude that the final obstruent in sonorant-obstruent clusters is not parsed into the same constituent as the last vowel in the word, and therefore cannot influence the length of that vowel.

\subsubsection{The complete ranking}

The complete ranking is shown in figure 1, collapsing those ranking conditions identified above that follow from transitivity of domination. The figure also collapses the distinction between different types of moraic markedness constraints acting against consonants. The reader may verify that all ranking conditions identified in previous sections are satisfied. An advantage of this approach is that it can be accommodated even within a theory which assumes a universal sonority-based hierarchy of moraic markedness (Zec, 1988; Morén, 2001; de Lacy, 2006), since nothing is inconsistent if the * $\mu$ [cons] node in figure 1 is "exploded" to reflect the universal ranking.

The dashed lines leading to WEIGHT BY POSITION[rhotic] reflect its different status across varieties: recall that it has to be dominated by EXTRAMETRICALITY (since there are no varieties where final rhotics receive a mora), but whether it is dominated also by moraic markedness is a point of variation. If it is not, vowels before rhotics in clusters are short; if it is, such vowels are long. In the latter case, the line from EXTRAMETRICALITY to WEIGHT BY POSITION[rhotic] is unnecessary, since the ranking then follows from transitivity of domination. Similarly,

\footnotetext{
${ }^{23}$ While I do not reject Richness of the Base out of hand, I do adhere to a restricted version which recognizes that the principle of Freedom of Analysis does not mean that GEN creates all logically possible candidates. The generation module "freely exercis[es] the basic structural resources of the representational theory" (Prince and Smolensky, 1993, p. 6), and therefore it should be possible for some logically conceivable candidates to be excluded from the set of candidates fed to EVAL; for extensive discussion, cf. the papers in Blaho et al. (2007); cf. also Scheer's (2011) notion of "sovereign arbitral award".
} 


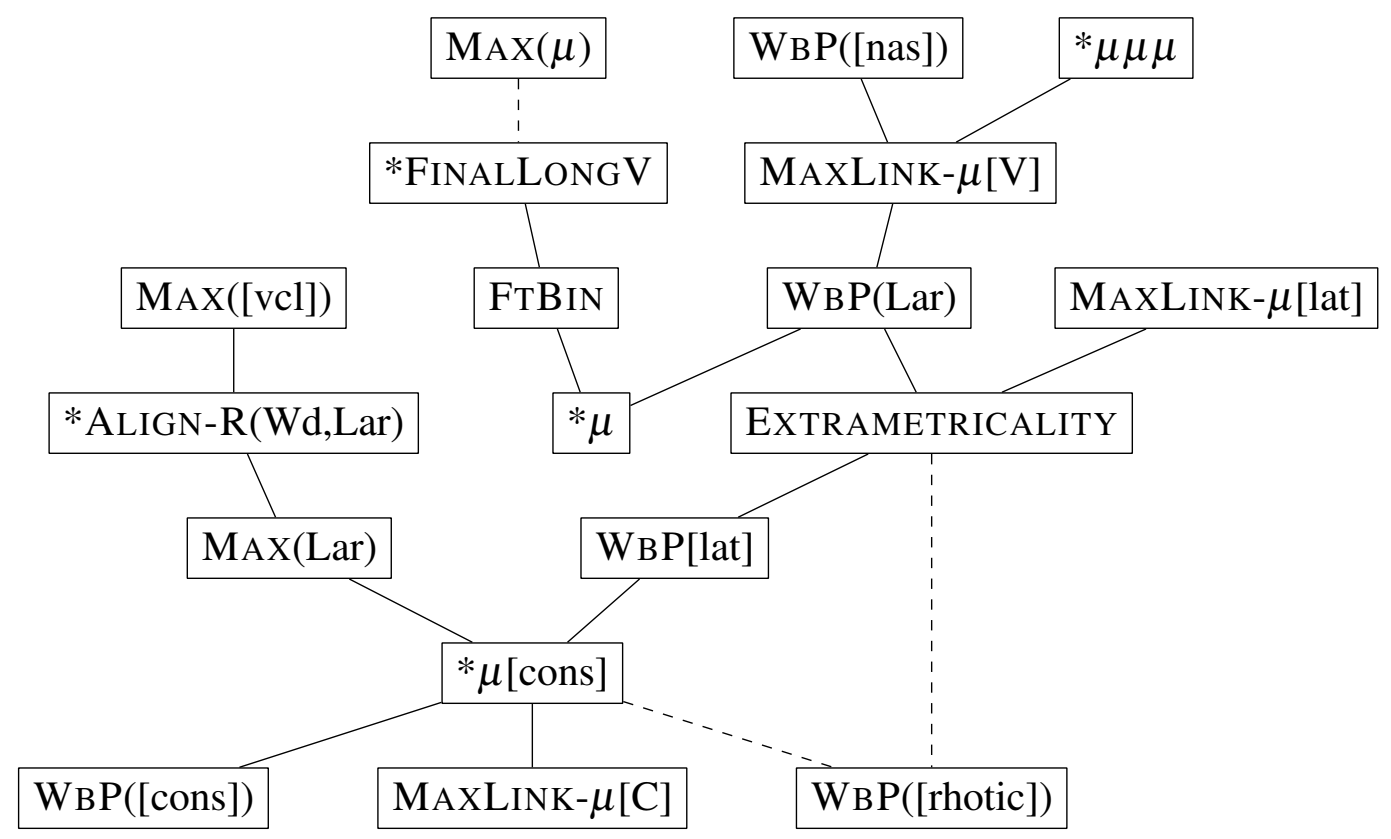

Figure 1: The complete ranking

the dashed line between MAX- $\mu$ and *FINALLONGV reflects the fact that variation in their ranking corresponds to the difference between how different varieties treat the vowel length contrast in final open syllables.

The full ranking reveals one counterfactual prediction of the present account: MAXLINK $-\mu[\mathrm{V}]$ dominates $\mathrm{WBP}[\mathrm{lat}]$ via a chain of ranked constraint pairs. This is undesirable because inputs with long vowels before [1]-obstruent clusters cannot use $\mathrm{WBP}$ [lat] to compel vowel shortening, as shown in (41).

No shortening before lateral-obstruent clusters

\begin{tabular}{|r||c|c|c|}
\hline \multicolumn{1}{|r|}{$\mathrm{ca}_{\mu \mu} \mathrm{ld}$} & $* \mu \mu \mu$ & MAXLINK- $\mu[\mathrm{V}]$ & WвP[lat] \\
\hline \hline a. $\odot \mathrm{ca}_{\mu} \mathrm{l}_{\mu} \mathrm{d}$ & & $* !$ & \\
\cline { 1 - 4 } b. $\mathrm{ca}_{\mu \mu} \mathrm{ld}_{\circ}$ & & & $*$ \\
\hline c. $\quad \mathrm{ca}_{\mu \mu} \mathrm{l}_{\mu} \mathrm{d}$ & $* !$ & & \\
\hline
\end{tabular}

I would suggest, however, that accounting for attested forms and alternations takes priority over excluding hypothetical forms provided by Richness of the Base, and all the ranking conditions involved in the chain between MAXLINK- $\mu[\mathrm{V}]$ and 
Wв P[lat] find empirical support in such alternations. The ranking for laterals does cover the fact that there is no lengthening between non-final laterals, and therefore the proposal remains empirically accurate. I discuss the Richness of the Base issue in more detail in section 4.5.

In the following section I provide a comparison of the present approach with previous accounts of Friulian phenomena and discuss some relevant conceptual issues.

\section{Discussion}

\subsection{Alternative accounts}

Vowel lengthening in Friulian and related varieties has been the subject of a number of formal studies set within a variety of frameworks. While all these accounts achieve good empirical coverage, in this section I argue that the present paper has a number of conceptual advantages.

\subsubsection{Lengthening as a compensatory phenomenon}

Hualde (1990) proposes an account in terms of moraic theory. He argues that the lengthening of vowels before underlyingly voiced obstruents is an instance of opacity. Specifically, he assumes that voiced coda obstruents project a mora at some intermediate level of representation, in line with the preference for highersonority codas discussed above. Final devoicing leads to delinking of the mora, which is then reassociated to the vowel, leading to lengthening. Thus, in Hualde's account, final devoicing counterbleeds weight-by-position, creating opacity.

This account, which essentially recapitulates the version of the historical development suggested by Francescato (1966); Vanelli (1979), is not reproducible in a parallel version of Optimality Theory, and thus Friulian data would appear to be problematic for parallel OT. However, Hualde's (1990) approach suffers from conflating lexical voiceless obstruents and those that are devoiced by the computation; in particular, he has to assume that both classes of voice-less obstruents are not moraic, which is inconsistent with both the duration data provided by Baroni and Vanelli (2000) and the behaviour of Italian borrowings (see below). Conversely, taking the ternary phonetic distinction into account in the phonology is precisely the reason why the present approach is able to provide a straightforward account in terms of parallel OT.

The approach employed by Hualde (1990) is of course potentially translatable into some serial version of OT, such as Stratal OT (Kiparsky, 2000; BermúdezOtero, forthcoming) or some version of Harmonic Serialism (McCarthy, 2007); 
see the next section. I would suggest, however, that the account proposed in the present paper is preferable because it does not only capture the relationship between final devoicing and vowel lengthening, but also does so in a manner which unifies these phenomena with the ternary surface contrast. The fact that, contrary to appearance, the phenomena studied here do not involve phonological opacity, is merely an added bonus. It is not my purpose here to argue for or against fully parallel vs. serial approaches to OT: the proposed model is equally valid in both of these frameworks.

\subsubsection{Harmonic serialism approaches}

A slightly different account is proposed by Torres-Tamarit (forthcoming), building on Montreuil's (2010) approach to Eastern Regional French. These accounts, couched in derivational versions of OT, also assume that underlyingly voiced obstruents project a mora while voiceless ones do not. However, unlike Hualde (1990), these authors propose that lengthening of the vowel is due to mora sharing rather than deletion and relinking, and that it is driven by the necessity to license morae by vowels; the surface representation for Alsatian French [ba:k] derived from underlying [bag] 'ring' is shown in (42).

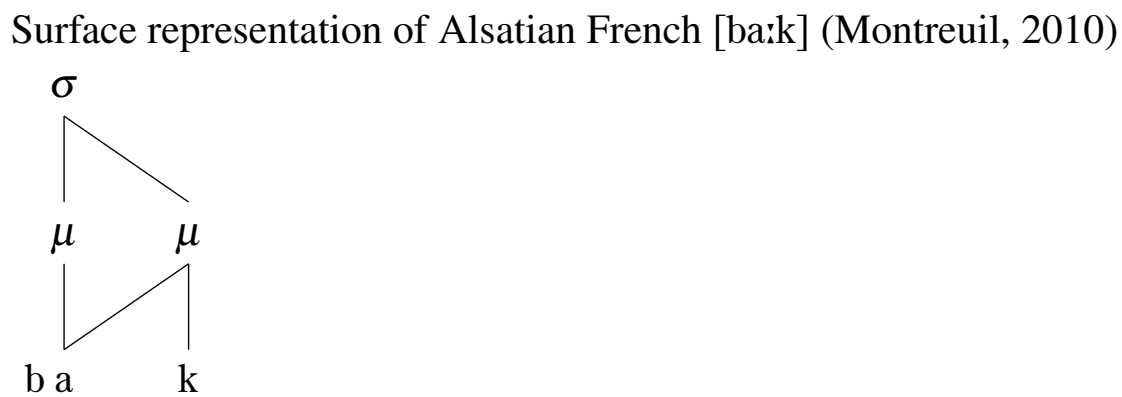

This account has the advantage that it disposes of the necessity to relativize weightby-position to analyse the obstruents: in this account, there is a single weightby-position constraint ranked above all relativized $* \mu$ constraints except those prohibiting moraicity of voiceless obstruents. However, the projection of the consonantal mora is still opacified by final devoicing, requiring a multiple-step derivation - arguably more complex than the present parallel account. In addition, Torres-Tamarit (forthcoming) does not derive the phonetic facts correctly, since he assumes complete neutralization; perhaps more seriously, in his account the devoiced obstruents are moraic, but voiceless ones remain nonmoraic, and since lengthening is not driven by foot binarity, the vowel remains short. As dis- 
cussed below in section 4.1.5, this is exactly the opposite of what the Friulian phonetic data would lead us to expect.

I conclude that the serial OT account can obviate the need for many of the proposals contained in this paper, but this happens at the cost of introducing an opaque derivation ${ }^{24}$ and potentially compromising empirical adequacy in terms of the phonology-phonetics interface. The kind of mora sharing advocated by Montreuil (2010) and Torres-Tamarit (forthcoming) is also more complex than the straightforward binarity advocated in the present paper.

\subsubsection{The length alternation as a shortening}

Repetti (1994) proposes a different model of the relationship between vowel length and voicing in Friulian. In her account, couched within a rule-based theory of prosody, the vowel length difference in ['la:d] versus ['lat] reflects an underlying vowel quantity contrast. This means that these forms are derived from /la:d/ and /lat/ respectively. She assumes that syllables in Friulian are maximally bimoraic and that Friulian also allows degenerate syllables. However, degenerate syllables can only be headed by voiced consonants (obstruents or sonorants). Therefore, Repetti accounts for the possibility of /la:d/ by assuming that devoicing counterbleeds degenerate syllable formation. A hypothetical input /lart/ would not be able to surface, since the voiceless obstruent cannot project a degenerate syllable.

There are several issues with this approach. First, it fails to derive the ternary contrast on the surface (unless we stipulate that the [d] type of pronunciation is associated with degenerate syllable nuclei, though why that would be the case remains somewhat mysterious). Second, Repetti (1994) assumes that vowel length in ['lart] 'gone (masc.)' is underlying, and therefore has to propose metrical shortening in [lade] 'gone (fem.)'. This analysis falls foul of the existence, in some varieties, of unshortened forms such as [ma:ri] 'mother' noted in (1). Repetti's approach to bimoraicity also forces her to postulate mora sharing in the case of coda clusters, which, as discussed by Baroni and Vanelli (2000), weakens the predictions of the theory: if mora sharing is available in cases such as ['alt] 'high' (where the entire coda shares a mora), it is not clear why inputs such as /'lait/ cannot survive via a single mora dominating both the coda and the nucleus. Repetti (1994) acknowledges this problem, but simply stipulates that mora sharing be-

\footnotetext{
${ }^{24}$ Note that Torres-Tamarit (forthcoming) uses Harmonic Serialism, which permits him to avoid stipulating the ordering of prosodic structure building and devoicing. This is arguably an advantage over Montreuil (2010), who couches his account in OT with Candidate Chains (McCarthy, 2007) and stipulates this ordering via PREC constraints.
} 
tween a vowel and a consonant is impossible. ${ }^{25}$ Finally, Repetti (1994) assumes that underlying /la:t/ cannot surface (certainly not as ['la:t]), and this prediction appears to be disconfirmed by the forms ['po:k] 'few' and ['o:k] 'gander' — with the caveat that it is unknown at this stage whether the final obstruents are indeed voiceless.

I conclude that most previous accounts of Friulian achieve reasonable empirical coverage, at least with respect to the obstruents: most of them do not contain a unified explanation for the behaviour of coda consonants in this language. However, none of them can do away with the opacity implied by failing to recognize the existence of the surface ternary contrast. I suggest, therefore, that the present account allows for a more straightforward approach to both phonetic and phonological aspects of the relationship between vowel length and laryngeal features in Friulian.

\subsubsection{A radically substance-free approach}

David Odden (p. c.) points out that since the evidence for the distinction between what I transcribe as [d] and [d] is purely phonetic, the assumption that these are two phonologically distinct entities is unwarranted in a radically substancefree theory. In other words, if we allow sufficient latitude in the phoneticsphonology interface, we can assume a binary contrast and treat the word-final obstruent in ['la:d] 'gone (masc. sg.)' as bearing a [voice] feature on the surface. In this case, an alternative account is available which assumes a moraic structure like that shown in (42) - but without opacity, since the licensing of the consonantal mora by the voicing feature would be surface-true - and otherwise follows Torres-Tamarit (forthcoming). Thus, such an approach would share the drawbacks of Torres-Tamarit's (forthcoming) account, in particular in relation to the phonetic interpretation of moraicity.

The radically substance-free analysis is attractive from a number of perspectives: for instance, if there is no laryngeal neutralization, the preservation-of-themarked argument for the high markedness of voicelessness disappears, and relativized weight-by-position becomes unnecessary for obstruents. However, it also faces problems, in particular with the sonorants: why would the mora projected by a lateral require additional licensing by a vowel (to achieve lengthening in ['va:l]) when one projected by a nasal does not require such additional licensing?

\footnotetext{
${ }^{25}$ Contrast the precisely opposite assumption made by Montreuil (2010); Torres-Tamarit (forthcoming).
} 
There are also a number of conceptual issues with this account, in particular with respect to the phonetics-phonology interface. Specifically, the assumption that [d] and [d] are not distinct phonologically rests primarily on the fact that the distinction is not used for lexical contrast and that the relevant segments do not show differences in phonological behaviour. I would suggest, however, that maintaining a phonological distinction in the face of such a situation is an option that cannot be excluded on principled grounds if we take seriously the project of coupling a non-trivial theory of representations with a computation that is free in manipulating these representations. The power of OT in manipulating representations is what stands behind the computational turn (e.g. Kirchner, 1997), and it cannot be arbitrarily abrogated. If we assume that $\langle$ Root $\rangle,\langle$ Root,Lar $\rangle$, and $\langle$ Root,Lar,[vcl] $\rangle$ are all possible distinct representations, there is no principled way to prevent the computation from designating all three as licit outputs, even if some of them stand in complementary distribution. This is especially so if there is in fact robust phonetic evidence for a difference, as in the case of Friulian: while it is possible that the categorical difference between phonetic [d] and [d] is introduced by the interface based on prosodic position, I suggest that it is better to view the phonetic distinction as the direct result of the interpretation of different featural structures. In particular, this would allow us to retain the phonetics-phonology interface as a purely interpretative component that does not introduce arbitrary categorical distinctions absent in the phonology.

\subsubsection{Length and laryngeal features}

The strong relationship between laryngeal features (and more specifically voicelessness) and length found in Friulian is by no means typologically unusual: there are many languages where voiceless segments (often more traditionally analysed as [spread glottis]) are associated with greater length. For instance, van Oostendorp (2003) argues that [spread glottis] fricatives in many Western Germanic varieties (including Standard Dutch) can only appear postvocalically if they are linked to two segmental slots. Similarly, in some dialects of Welsh [spread glottis] stops cannot be preceded by long vowels (Awbery, 1984), which suggests an analysis somewhat similar to the Friulian.

An anonymous reviewer asks whether the laryngeal opposition in Friulian can be analysed as a pure quantity contrast, with voiceless obstruents represented as long and voiced ones represented as short. The key components of such an analysis would be as follows:

- The rhyme in a stressed syllable is strictly bipositional; 
- There is extrametricality of the final slot. The reviewer further suggests that this extrametricality can be driven by a constraint prohibiting place specifications at the right edge of the syllable rather than a separate EXTRAMETRICALITY constraint;

- Thus, in words ending in a voiceless obstruent the final slot of that obstruent would be extrametrical because of maximum binarity, whereas the initial one would be parsed into the coda (but still keep its place specification due to faithfulness), leaving no room for vowel lengthening. A word such as ['lat] 'milk' would be analysed as [lat] $\langle\mathrm{t}\rangle$;

- In the case of word-final voiced obstruents, lengthening is a device to simultaneously achieve binarity and underparse the place-specified consonant: $[\mathrm{laa}]\langle\mathrm{t}\rangle$ gone (masc. sg.)';

- Single nasals can be freely parsed into the coda if we assume they are placeless (see footnote 1), meaning there is no reason to lengthen: [man] 'hand';

- The absence of lengthening before some laterals can be achieved similarly to the present account, by assuming a geminate lateral, leading to a parse like [val] $\langle 1\rangle$ for 'valley'. Lengthening before a single [1] can be motivated, for instance if we assume that [1] has a place specification, ${ }^{26}$ which means that lengthening can be deployed in a way similar to the case of the voiced obstruents;

- The lack of short vowels before single [r] can be due to a prohibition on double association of the latter segment;

- Shortening before clusters comes more or less for free.

As the reviewer points out, such purely quantitative systems are found, for instance, in Thurgovian German (Kraehenmann, 2001, 2003); in fact, Seiler (2009) argues that most High German dialects originally had or indeed still have this type of contrast (see also Lahiri and Kraehenmann, 2004).

\footnotetext{
${ }^{26}$ This is not impossible even in a theory based on contrastive specification: in terms of the contrastive hierarchy (Dresher, 2009, et passim) this is easily achieved by putting place features high on the hierarchy
} 
While an account along these lines has important merits, ${ }^{27}$ I would suggest that even if it were to be accepted in preference to the one proposed in this paper, many of the key points of the latter would remain intact. For instance, a cornerstone of the present account is the assumption that voiceless obstruents are more marked, in the precise sense that they have more structure, rather than in a diacritic sense; the quantitative approach expresses the very same intuition (which goes against standard assumptions) rather directly.

However, the length-based approach shares with other previous accounts the incorrect assumption that Friulian only allows two laryngeal categories in the output of its phonology. This is not a problem per se given a sufficiently complicated phonology-phonetics interface, but I suggest that the quantity-based account faces serious challenges. For instance, devoiced obstruents could be analysed as the phonetic implementation of an unparsed single obstruent. Yet Baroni and Vanelli (2000) find that word-final voiceless obstruents are longer than wordinternal voiceless obstruents, even though the account predicts the former to be underparsed and the latter to be fully parsed. Under the proposal in the present paper, the difference between devoiced and voiced obstruents is directly represented featurally, while the difference in length between word-internal and word-final voiceless obstruents follows from moraic structure.

This problem is not fatal to the quantity-based approach: once we allow a phonology-phonetics interface with sufficient latitude to interpret a quantity contrast as a laryngeal opposition, there is probably no principled way of preventing it from realizing an underparsed geminate as a longer segment than a parsed one. ${ }^{28}$

\footnotetext{
${ }^{27}$ Since I do not pursue this account in detail, I gloss over some of its potential weaknesses, such as the apparent inability to derive long vowels before [rC] sequences, the unclear status of affricates (since the length contrast is recruited to express laryngeal oppositions, the behaviour of the affricates cannot be unified with that of the clusters), and Richness of the Base issues (for instance, it is not clear whether an input /laatt/ would give a surface representation that is licit in Friulian).

${ }^{28}$ An approach deriving laryngeal features purely from quantity is not unprecedented: this is exactly how Carlyle (1988) analyses Léonais Breton, using redundancy rules such as "an obstruent becomes [-voice] when it is single and word-final, [-voice] when it is long, and [+voice] otherwise" (p. 62). (For Carlyle these rules are part of the phonology, but since [voice] is all but inactive in her analysis, it is possible to interpret them as descriptions of the interface; I abstract from some details here) Léonais Breton, however, sides with Thurgovian German rather than Friulian in that the phonological length is actually realized in the phonetics as well (Falc'hun, 1951). Another example is Pöchtrager's (2006) proposal, couched in a version of Government Phonology, to completely replace laryngeal features (or at least the $\mathrm{H}$ element, i. e. voicelessness) with structural configuration.
} 
However, I would suggest that my proposal allows for a much more straightforward and less arbitrary mapping between phonetic and phonological representations.

Overall, the quantity-based account has a number of strengths. For instance, it allows for an elegant unification of word-final phenomena such as devoicing and neutralization of the place contrast in nasals with extrametricality, and it can potentially undermine the argument against the universal sonority hierarchy, if the differences in sonorant behaviour can be explained in terms of, say, place specifications. The balance of these strengths against its weaknesses is an interesting point in and of itself. I would suggest, however, that it does not undermine the most important points of the present paper, since it still shares several crucial assumptions with the present proposal, namely language-specific, non-universalist phonological representation, a highly non-trivial interface between phonology and phonetics, the correlation between markedness and structural size, and, somewhat more parochially, the greater markedness of voiceless obstruents in Friulian. In that sense, the differences between the present proposal and the quantity-based approach are rather minor.

\subsection{Markedness, contrastive specification and feature geometry}

The representational system proposed in the present paper relies on a version of feature geometry. Specifically, the paper explores the integration of a relatively orthodox feature geometry based on tiers and privative features with languagespecific feature specifications.

The basic idea is that the presence of a feature-geometrical node is the result of a contrastive specification procedure similar to the contrastive hierarchy of Dresher (2003, 2009); Hall (2007); for a similar proposal see Ghini (2001b). This is an instantiation of Hall's (2007) privative version of the Successive Division Algorithm (SDA). The original version of the SDA presented by Dresher (2003) uses binary features. This means that all segments which are contrastively specified for some feature bear some value for that feature, and segments for which this feature is not contrastive do not bear a value. However, the drawback is that there is no way to distinguish which value of the feature behaves as more marked in the system. This means that a contrastive hierarchy using binary features will not be able to directly reproduce markedness effects other than the asymmetry between the presence and absence of a specification. More nuanced markedness effects similar to those explored by de Lacy (2006) can only be accounted for in terms of diacritics designating certain feature values as marked. 
This "excessive symmetry" problem does not arise with privative features, as argued by Hall (2007). As I have shown in section 2, following Causley (1999); Rice (2003), asymmetries in the amount of structure can reproduce markedness effects without stipulations such as universal markedness hierarchies: effects such as markedness reduction and preservation of the marked fall out from the logic of constraint-based evaluation. However, the purely privative approach of Hall (2007) has the undesirable property of failing to distinguish those segments for which a given privative feature is not distinctive (those which lack it in the binaryfeature version) and those for which its lack is distinctive (those with the unmarked value of a binary feature). In other words, only a binary contrast is allowed along a single dimension. The existence of ternary contrasts such as those found in Friulian falsifies this prediction.

I propose that the use of arboreal structures to capture ternary contrasts is not just a notational variant of binary features (Wetzels and Mascaró, 2001; Uffmann, 2009), and in fact it has important advantages:

First, feature geometry reproduces the distinction between contrastive nonspecification and lack of contrastive specification (Ghini, 2001b). Second, featuregeometrical structure reproduces markedness effects directly thanks to stringent constraint violation sets rather than via stipulative assignment of a markedness ordering on feature values; see Rice (2003) for very similar arguments (but outside of the context of OT);

Finally, arboreal structures with privative features restrict spreading processes in a way that is unavailable with symmetric representations. Specifically, they allow for a distinction between spreading of a node and spreading of a feature; coupled with restrictions on potential landing sites (Avery and Rice, 1989; Piggott, 1992; Inkelas and Cho, 1993; Avery, 1996), this makes it possible to express generalizations such as "segments for which $[\mathrm{F}]$ is not contrastive are transparent to spreading of $[\mathrm{F}]$ " (formalized as the lack of the node dominating $[\mathrm{F}]$, meaning that the relevant segment is not a potential target for $[\mathrm{F}]$ spreading). In theories without feature-geometrical restrictions (a recent example is Nevins, 2010), these generalizations can only be expressed by diacritic marking of some values as "marked", "non-contrastive" etc. While feature geometry is certainly not the full answer to problems of locality (Odden, 1994), I nevertheless suggest that it allows for a unification of markedness and locality in spreading that remains rather mysterious under less representationally elaborate approaches. 


\subsection{Relativized weight by position versus fixed rankings}

Another aspect in which the present paper departs from assumptions made in much of earlier scholarship is the introduction of weight-by-position relativized to certain featural combinations. A more standard approach to coerced weight (i. e. surface weight not due to underlying contrasts) is to use a general constraint enforcing moraicity (such as WEIGHT BY POSITION) interspersed with constraints of the form $* \mu[\alpha]$ arranged in a fixed ranking (Morén, 2001). The place of WEIGHT B Y POSITION in the hierarchy determines the sonority cut-off point for possible moraic segments in the language.

There are two reasons why this solution is not satisfactory for Friulian. First, as we have seen in section 4.4, the empirical adequacy of the fixed ranking is in doubt for Friulian, at least in the case of obstruents. Second, given the representational assumptions of this paper, the lack of moraicity for delaryngealized obstruents could only follow if WEIGHT BY POSITION were outranked by a constraint militating against moras associated with segments lacking a laryngeal specification. This is problematic from a formal perspective: such a constraint is formally an augmentation constraint since requiring the presence of some structure in some context, whereas more standard moraic markedness constraints require the absence of structure. Moreover, assuming that such a constraint is part of CON is problematic because a constraint militating against moraic segments lacking a Lar node also militates against sonorant weight. ${ }^{29}$ If such a constraint dominates WeIGHT BY POSITION, the prediction is a system where only obstruents are moraic, going against the grain of most predictions regarding coda sonority. What is worse, in a system without a device actively singling out sonorants for weight (as WEIGHT BY POSITION[nasal] does here), there is no way to ensure that sonorants are moraic after all. Thus, having a constraint against laryngeally unspecified moraic obstruents is problematic both formally and empirically, yet it appears inevitable if the representational proposal made in this paper were to be adapted to a theory of moraicity based exclusively on a fixed-ranking hierarchy.

The perspective adopted in the present paper, on the other hand, directly connects a segment's featural specifications or lack thereof with its ability to license moraicity, achieving empirical coverage of the Friulian pattern in the process. It is true that the ability to rerank WeIGHT By POSITION $[\alpha]$ vis-à-vis $* \mu[\alpha]$ weakens the empirical predictions, but this it appears inevitable in view of the data discussed in section 4.4 (see also footnote 30 on page 48 for discussion).

\footnotetext{
${ }^{29} \mathrm{At}$ least in languages where voicing is not a distinctive feature for sonorants.
} 


\subsection{The universality of markedness hierarchies}

The theory of markedness hierarchies presented by de Lacy (2006) relies on multi-valued features like [Place], with a fixed universal mapping between the values of these features and phonological objects such as [coronal]. However, the universality of this mapping is not strictly necessary to derive markedness effects: this is an additional hypothesis, which restricts the possible variation space by excluding the existence of two languages where the order of phonological features on the markedness hierarchy is reversed. In de Lacy's (2006) proposal, processes which seem to require an increase in markedness along a scale obeyed by other languages can only be due to hierarchy conflict, rather than to representational differences among the relevant languages.

The present theory, on the other hand, allows for the possibility that [voiceless] obstruents are the most marked ones on Friulian, on the basis of them exhibiting preservation-of-the-marked behaviour in word-final delaryngealization. In other words, I argue that while markedness relationships within a language work in ways similar to those envisaged by de Lacy (2006), thanks to the architecture of constraint violations, the non-universal assignment of featural specifications means that markedness hierarchies across languages can vary depending on the structure of the specifications (cf. also Rice, 1996, 2003). Friulian illustrates this point on at least two counts.

First, as mentioned above, Friulian voiceless obstruents act as the most marked member of the system of laryngeal oppositions, since they are not the outcome of final laryngeal neutralization. In a "normal" case of final devoicing, one assumes that [voice] represents the marked member of the opposition, and that final devoicing is merely an unfaithful mapping deleting this marked value (for extensive discussion in terms of a privative theory, see Harris, 2009) and resulting in the appearance of the less marked structure, identified with [-voice] (or no element in privative approaches). However, as we have seen, devoicing in Friulian does not create voiceless obstruents. To the contrary, Friulian voiceless obstruents resist the word-final markedness-reducing process, which is a hallmark of highly marked elements. This is at odds both with the general "voicing hierarchy" and with the preference for high-sonority coda.

The discrepancy with regard to the coda sonority hierarchy is even more striking. The standard assumption is that codas prefer higher-sonority segments; importantly, this insight is couched in moraic terms. One reason for this is because the sonority of codas often plays a rôle in the computation of weight for the purposes of stress or templatic morphology. Many relevant cases are documented by Zec (1988); Morén (2001); Gordon (2006). 
However, in Friulian the situation is reversed: as we have seen, voiceless obstruents cannot be preceded by a long vowel, which receives a natural explanation in terms of a preference for their moraicity coupled with a maximum-binarity requirement. The evidence for the moraic status of voiceless obstruents is not restricted to the facts I focused on in this paper:

- As noted in section 1.3, Baroni and Vanelli (2000) find that voiceless stops are phonetically longer than both voiced stops and word-final delaryngealized ones;

- Italian borrowings (Vanelli, 1979, 1986; Baroni and Vanelli, 2000) show that Friulian speakers attend to the moraic status of the source obstruents rather than to their actual laryngeal specification. Italian voiceless singletons (which are not moraic, cf. D'Imperio and Rosenthall, 1999; Krämer, 2009) are borrowed as voiced singletons, while Italian voiceless geminates are borrowed as voiceless singletons: Italian impiegato 'clerk' becomes Friulian [impje'ga:d] (and feminine impiegata becomes [impje'gade]), whereas affitto 'rent' becomes [a'fit] (cf. the diminutive [afi'tut]);

- Baroni and Vanelli's (2000) data on pitch appear consistent with the suggestion that a voiceless obstruent forms a single bimoraic constituent with a preceding short vowel. Specifically, vowels before delaryngealized obstruents $\left(\left[\left(\mathrm{la}_{\mu \mu}\right) \mathrm{d}\right]\right.$ under the present interpretation) bear with a HL contour, while vowels before voiced stops $\left(\left[\mathrm{la}_{\mu} t_{\mu}\right]\right)$ have a late $\mathrm{H}$ peak; this can be explained if we assume the $\mathrm{H}$ tone to be timed near the end of the first mora.

The point of this section is to demonstrate that the assumption of universal feature specification and universal markedness hierarchies appears to be too strong, and that a substance-free approach to phonological representation presents a relaxed but still restricted alternative. Specifically, while there is more choice in the assignment of featural specification, the predictions for markedness-related behaviour within a language still hold. ${ }^{30}$

\footnotetext{
${ }^{30}$ Coda-sonority reversals often involve obstruent voicing, while facts that challenge the hierarchy with respect to sonorants are more difficult to come by. Nevertheless, we have seen that Friulian does treat nasals as more desirable moraic segments than rhotics; cf. also the study of variation in relative sonority of [1] and [r] by Rice (2005). This is an interesting fact which cannot be explored in detail here. I will make two brief remarks. First, in a theory which eschews a universal feature set and cross-linguistically consistent assignment of feature specifications, for-
} 


\subsection{Length, richness of the base, and history}

Finally, the account of Friulian vowel lengthening developed in this paper provides an opportunity to discuss the respective roles of phonological computation and history in accounting for synchronic sound patterns. ${ }^{31}$

In the present paper I have followed a large body of existing work on Friulian in assuming that the alternating vowels in final syllables are underlyingly short and only lengthen when compelled to do so by foot binarity requirements. I have also argued that long vowels in word-final closed syllables surface faithfully.

There are two potential issues with this account. First, it presents a number of problems related to Richness of the Base. Second, the assumption that long vowels before word-final devoiced obstruents are the product of lengthening runs contrary to the historical reconstruction of developments in Gallo-Romance and northern Italo-Romance which gives a prominent rôle to the distinctive status of vowel length; see in particular Morin (2003), and also Loporcaro (2007, 2011b) for relevant discussion.

In order to better understand these issues, a short historical sketch is in order. According to Morin (1992, 2003); Loporcaro (2007, 2011b), vowel length in forms such as ['la:d] 'gone' represents a remnant of the long vowel which arose by open syllable lengthening (OSL) in Vulgar Latin *LATUM, while the short vowel in ['lat] 'milk' continues a vowel that was not lengthened in a closed syllable (LACTEM). The basic Friulian pattern arose because singleton obstruents underwent lenition (Loporcaro, 2011a), which excluded voiceless singletons from the position following a vowel lengthened under OSL, and thus established the connection between voicing and vowel length. Importantly, in Friulian voiced geminates appear to have fallen together with voiced singletons, as shown by

mulating a universal hierarchy à la Morén (2001) is impossible in any case. This means that an explanation for coda-sonority facts could be sought in functional and/or historical factors rather than some universal property of synchronic phonological computation. This might be not very satisfying for those committed to explaining the extent of variation solely in terms of constraint reranking, but still remains a possibility (Kavitskaya, 2002; Blevins, 2005; Barnes, 2006; Mielke, 2007; Yu, 2007; Reiss, 2007). Second, issues related to the featural representations of sonority remain unresolved at this point. If all sonority can be defined in terms of featural specifications, as has often been attempted especially in Government Phonology and Element Theory approaches (cf. Harris, 2006; Cyran, 2010), interesting patterns may yet emerge from the interplay of subset relations among sonorant representations and consequent stringency of constraint violation sets. I leave this matter for further research.

${ }^{31}$ I am grateful to an anonymous reviewer for many perceptive comments on the issues discussed in this section. 
the presence of lengthening in forms such as ['fresd] 'cold' from *FRIDDUM $\leftarrow$ *FRIG(I)DUM. In this respect, Friulian crucially differs from other dialects such as Milanese, where historical voiced geminates appear to block lengthening: ['fred] 'cold', ['gøb] 'hunchback', from *GUBBUM (Morin, 2003). ${ }^{32}$

Data such as those in Milanese appear to require a bigger role for distinctive moraicity than the Friulian situation. In section 3.3.3 I argued that Friulian grammar maps rich-base inputs with a moraic voiced or delaryngealized obstruent to outputs with a non-moraic consonant (and thus a long vowel), creating a licit configuration. Languages like Milanese could be accounted for with a higher ranking of faithfulness to moraic association, which would ensure a lack of vowel lengthening even despite delaryngealization, giving surface forms such as ['g $\left.g \varnothing_{\mu} \mathrm{b}_{\mu}\right]$. Otherwise the account would be all but identical to the Friulian one, with long vowels before devoiced obstruents being the product of lengthening. ${ }^{33}$

With such a prominent role assigned to phonological manipulation of underlyingly short vowels, the behaviour of long vowels remains to be discussed. In some respects, the present account is overgenerating. Specifically, while the ranking discussed in section 3 does ensure that most input forms with long vowels in final syllables do not map to phonotactically irregular outputs, the high ranking of faithfulness to underlying vocalic length predicts a number of unattested alternation patterns. For inputs of the type /'lait/, the predicted alternation pattern, as we have seen, is ['la:t] ['la:tV], and while the examples are not numerous, the prediction appears to be borne out. On the other hand, input $/ \mathrm{la}_{\mu \mu}: \mathrm{d} /$ produces the unattested pattern [la:d] $\sim$ [la:dV]. ${ }^{34}$ Similar pathologies exist for syllables ending in sonorants: while the ranking in figure 1 excludes most phonotactically deviant forms in final syllables, it also produces unattested patterns with a long vowel in the penultimate syllable.

The explanation for this particular gap is ultimately historical (cf. here Blevins, 2005 , et passim). The alternation pattern is associated with vowels that continue

\footnotetext{
${ }^{32}$ The question of whether the Friulian development is due to an early degemination or to a later restructuring of the system is an interesting one, but far beyond the scope of this paper (also see Morin, 2003, fn. 15 for specific discussion of Friulian ['fre:d]). Affricates are also obviously a special case here.

${ }^{33}$ A potential prediction would appear to be that in Milanese devoiced obstruents after short vowels would be longer phonetically than devoiced obstruents after a long vowel, in parallel with the facts discussed for Friulian in section 4.1.5. I am not aware of relevant instrumental studies, and treat this as a falsifiable prediction at this stage.

${ }^{34}$ However, neither form is phonotactically irregular.
} 
pre-OSL short vowels in open syllables. The surface distribution of length on these vowels was predictable on the basis of quantity of the following consonant, and remains so in Friulian, even though the quantitative contrast has been reinterpreted in qualitative terms. This assumption is not at odds with viewing long and short vowels as phonologically distinct representations, as Morin (2003) insists. Any phonological system with a non-trivial computational component can manipulate representations to achieve predictability (e.g. complementary distribution); however, the existence of such predictability does not automatically entail a lack of phonological distinctness.

Vowels that behave unpredictably with respect to the alternation are precisely those that were not caught up in the process of OSL followed by intervocalic lenition which gave rise to the patter. Words such as ['po:k] (*PAUCUM), ['ork] (AU(I)CUM) exemplify length that is not derived by OSL (but rather by diphthongization), with the stops protected from voicing by the diphthong's offglide. Similarly, in forms such as ['vo:li] 'eye' and ['fra:di] 'brother' the long vowels are due to lengthening before historical muta cum liquida sequences. ${ }^{35}$ Thus, the lack of attestation of words where an underlying long vowel can appear in a final syllable has a historical explanation: there are very few pathways of change that would create morphemes with a long vowel followed by a single voiced obstruent or a sonorant, and in addition the relevant structure is often not final in the word. Long vowels before sonorants never appear in a final syllable because such sonorants are always followed by a vowel, for historical reasons (Heinemann, 2007). ${ }^{36}$ The same applies to long vowels before obstruents derived from muta cum liquida sequences. The other source of underlying long vowels, historical *AU followed by a single consonant is relatively rare, and it appears that many cases involve feminines nouns with the suffix $-e$, as in ['robe] 'thing' (*RAUBA), ['cose] 'thing' (*CAUSAM), where the morphology does not permit the potential underlying long vowel to surface in a final syllable.

\footnotetext{
${ }^{35}$ In fact, it appears that at least in some varieties the long vowels derives from compensatory lengthening synchronically: Heinemann (2007) cites numerous dictionary examples of words related to voli 'eye' that demonstrate the root allomorph vogl-in unstressed position, such as voglon 'eye-augmentative' and voglâ 'to eye'.

${ }^{36} \mathrm{An}$ exception here is long vowels before [1], where the [1] can drop before the plural suffix, leading to the creation of what appears to be a diphthong, as in the dialect of Forni di Sotto: singular ['vo:li] 'eye', plural ['vo:i] (Heinemann, 2007, p. 168). I do not take up this matter further here due to the extensive variation; I do note that there is no shortening of the vowel in the final syllable at least in this variety, which is consistent with the present account.
} 
Finally, a similar historical explanation is available for the behaviour of vowels before word-final clusters. We have seen that underlying long vowels are predicted to surface faithfully before some sequences (two obstruents and [1]-obstruent), but this situation is quite rare; the far more frequent case is a short vowel, which does not lengthen in the pre-cluster context. Again, if we assume that underlying short vowels continue the Vulgar Latin penult vowels, there is no reason to expect that they would ever be long, since all vowels were short before obstruent clusters, as they still are in (Standard) Italian. The underlying long vowels in certain morphological contexts are also a later innovation, associated with the borrowing from Italian with the suffix -gge (Yamamoto, 1993).

I conclude that while the present account appears to overgenerate some alternation patterns, the explanation for their absence is found in language history. Specifically, vowels which descend from segments with predictable length in Late Vulgar Latin retain this predictability, albeit in an altered context, whereas the less predictable patterns deriving from later developments are much rarer, due to the phonological history of the language.

\section{Conclusion}

This paper has pursued two aims. First, I have presented a novel analysis of vowel lengthening and its relation to laryngeal features in Friulian. The most interesting aspect of the Friulian pattern is the near-exceptionless association of obstruent devoicing and vowel lengthening. I have shown it to follow straightforwardly from the inability of devoiced obstruents to license a mora due to losing their laryngeal specification. The key to the solution lies in closer attention to the empirical data, which show that "final devoicing" in Friulian does not in fact involve neutralization of the laryngeal contrast. This approach has opened the way to developing an account in fully parallel OT, without recourse to crucially ordered rules or input generalizations.

From a theoretical perspective, this paper is set within a framework which emphasizes the value of representations even within a theory such as OT, which has historically tended to downgrade their importance. I have proposed representational solutions to several questions that have relevance for the analysis of Friulian. Thus, I have shown that language-specific feature assignment allows us to capture sonority-related patterns that are not predicted by the standard OT approaches associating codas with high sonority, without at the same time compromising generalizations with respect to markedness behaviour within a single language. Specifically, I have argued that even though Friulian violates general- 
izations with respect to preferred coda sonority previously claimed to have universal status, this violation can be explained in terms of the featural and arboreal structure of phonological representations. Moreover, the use of articulated representations has allowed us not only to resolve the issue of the Friulian pattern's apparent opacity but also to derive generalizations with respect to markedness reduction and preservation without any additional mechanisms.

In general, I suggest that a more nuanced theory of phonological representation - one that both relies less on aprioristic assumptions with respect to how phonetics maps to phonology and vice versa and has a better foundation in empirical data - has the potential to cast new light on many empirical issues that have hitherto proved problematic for phonological theory. The present proposal can only be but a first step in this direction.

\section{Acknowledgements}

Versions of this paper were presented at the 18th Manchester Phonology Meeting and at Going Romance 24. I thank the audiences in Manchester and Leiden for constructive discussion, in particular Stefano Canalis, Marc van Oostendorp, Tobias Scheer and Ruben van de Vijver. I am also grateful to Bruce Morén-Duolljá, David Odden, Francesc Torres-Tamarit, and two anonymous referees for Lingua for comments that have greatly contributed to improving both analysis and presentation. The responsibility for any errors and infelicities is entirely mine.

\section{References}

Anderson, J., Ewen, C., 1987. Principles of Dependency Phonology. Cambridge University Press, Cambridge.

Aoun, J., 1979. Is the syllable or the supersyllable a constituent? MIT Working Papers in Linguistics 1, 140-148.

Avery, P., 1996. The representation of voicing contrasts. Ph.D. thesis. University of Toronto.

Avery, P., Rice, K., 1989. Segmental structure and coronal underspecification. Phonology 6, 179-200.

Awbery, G.M., 1984. Phonotactic constraints in Welsh, in: Ball, M.J., Jones, G.E. (Eds.), Welsh phonology: Selected readings. University of Wales Press, Cardiff, pp. 65-104. 
Backley, P., 2011. An introduction to Element Theory. Edinburgh University Press, Edinburgh.

Barnes, J., 2006. Strength and weakness at the interface: positional neutralization in phonetics and phonology. Walter de Gruyter, Berlin.

Baroni, M., Vanelli, L., 2000. The relationship between vowel length and consonantal voicing in Friulian, in: Repetti (2000). pp. 13-44. pp. 13-44.

Beckman, J., 1998. Positional faithfulness. Ph.D. thesis. University of Massachusetts, Amherst. Amherst.

Beckman, J., Jessen, M., Ringen, C., 2009. German fricatives: coda devoicing or positional faithfulness? Phonology 26, 231-268.

Bermúdez-Otero, R., forthcoming. Stratal Optimality Theory. Oxford University Press, Oxford.

Bethin, C.Y., 1992. Polish syllables: the role of prosody in phonology and morphology. Slavica Publishers, Columbus.

Blaho, S., 2008. The syntax of phonology: a radically substance-free approach. Ph.D. thesis. University of Troms $\varnothing$. Troms $\varnothing$.

Blaho, S., Bye, P., Krämer, M. (Eds.), 2007. Freedom of analysis? Number 95 in Studies in Generative Grammar, Mouton de Gruyter, Berlin.

Blevins, J., 2005. Evolutionary Phonology: The emergence of sound patterns. Cambridge University Press, Cambridge.

Boersma, P., 2009. Cue constraints and their interaction in phonological perception and production, in: Boersma, P., Hamann, S. (Eds.), Phonology in perception, Mouton de Gruyter, Berlin. pp. 55-110.

Boersma, P., Hamann, S., 2008. The evolution of auditory dispersion in bidirectional constraint grammars. Phonology 25, 217-270.

Buckley, E., 1992. Theoretical aspects of Kashaya phonology and morphology. Ph.D. thesis. University of California, Berkeley. Berkeley. Published 1994, Stanford: CSLI. 
Bye, P., de Lacy, P., 2008. Metrical influences on fortition and lenition, in: Carvalho, J.B.d., Scheer, T., Ségéral, P. (Eds.), Lenition and fortition. Mouton de Gruyter, Berlin. number 99 in Studies in generative grammar, pp. 173-2006.

Carlyle, K.A., 1988. A syllabic phonology of Breton. Ph.D. thesis. University of Toronto.

Causley, T., 1999. Complexity and markedness in Optimality Theory. Ph.D. thesis. University of Toronto. Toronto.

Charles-Luce, J., Dinnsen, D.A., 1987. A reanalysis of Catalan devoicing. Journal of Phonetics 15, 187-190.

Cyran, E., 2010. Complexity scales and licensing in phonology. Number 105 in Studies in Generative Grammar, Mouton de Gruyter, Berlin.

D'Imperio, M., Rosenthall, S., 1999. Phonetics and phonology of main stress in Italian. Phonology 16, 1-28.

Dinnsen, D.A., Charles-Luce, J., 1984. Phonological neutralization, phonetic implementation and individual differences. Journal of Phonetics 12, 49-60.

Dresher, B.E., 2003. The contrastive hierarchy in phonology, in: Hall, D.C. (Ed.), Toronto working papers in linguistics.

Dresher, B.E., 2009. The contrastive hierarchy in phonology. Cambridge University Press, Cambridge.

Ernestus, M., Baayen, R.H., 2006. The functionality of incomplete neutralization in Dutch: the case of past-tense formation, in: Goldstein, L.M., Whalen, D.H., Best, C.T. (Eds.), Phonetics and phonology: Laboratory Phonology 8, Mouton de Gruyter, Berlin. pp. 27-49.

Falc'hun, F., 1951. Le système consonantique du breton. Pilhon, Rennes.

Finco, F., 2007. La durata delle vocali friulane: risultati di un'indagine fonetica, in: Vicario (2007). pp. 119-140. pp. 119-140.

Finco, F., 2009. Fonetiche e fonologije dal furlan centrâl. Gjornâl Furlan des Sciencis $11,53-85$. 
Foley, J., 1977. Foundations of theoretical phonology. Number 20 in Cambridge Studies in Linguistics, Cambridge University Press, Cambridge.

Francescato, G., 1966. Dialettologia friulana. Società filologica friulana, Udine.

Frau, G., 1984. Friuli. Number 6 in Profilo dei dialetti italiani, Pacini Editore, Pisa.

Ghini, M., 2001a. Asymmetries in thee phonology of Miogliola. Number 60 in Studies in Generative Grammar, Mouton de Gruyter, Berlin.

Ghini, M., 2001b. Place of articulation first, in: Hall, T.A. (Ed.), Distinctive feature theory, Mouton de Gruyter, Berlin. pp. 147-176.

Gordon, M., 2006. Syllable weight: phonetics, phonology, typology. Routledge, London, New York.

Haiman, J., Benincà, P., 1992. The Rhaeto-Romance languages. Routledge, London, New York.

Hale, M., Reiss, C., 2008. The phonological enterprise. Oxford University Press, Oxford.

Hall, D.C., 2007. The role and representation of contrast in phonological theory. Ph.D. thesis. University of Toronto. Toronto.

Hall, D.C., 2009. Laryngeal neutralization in Breton: loss of voice and loss of contrast, in: Mailhot, F. (Ed.), Proceedings of the 2009 annual conference of the Canadian Linguistic Association.

Harris, J., 1997. Licensing Inheritance. Phonology 14, 315-370.

Harris, J., 2005. Vowel reduction as information loss, in: Carr, P., Durand, J., Ewen, C.J. (Eds.), Headhood, elements, specification, and contrastivity: papers in honour of John Anderson, John Benjamins, Amsterdam. pp. 119-132.

Harris, J., 2006. The phonology of being understood: further arguments against sonority. Lingua 116, 1483-1494.

Harris, J., 2009. Why final obstruent devoicing is weakening, in: Nasukawa, K., Backley, P. (Eds.), Strength relations in phonology. Mouton de Gruyter, Berlin. number 103 in Studies in generative grammar, pp. 9-46. 
Harris, J., Lindsey, G., 1995. The elements of phonological representation, in: Durand, J., Katamba, F. (Eds.), Frontiers of phonology: atoms, structures, derivations, Longman, Harlow, Essex. pp. 34-79.

Hayes, B., 1995. Metrical stress theory: principles and case studies. University of Chicago Press, Chicago.

Heinemann, S., 2007. Lo sviluppo di muta cum liquida e processi connessi in friulano ed in altri idiomi romanzi, in: Vicario (2007). pp. 141-180. pp. 141180.

Hjelmslev, L., 1975. Résumé of a theory of language. Travaux du Cercle linguistique de Copenhague, Nordisk Sprog- og Kulturforlag, København.

Hualde, J.I., 1990. Compensatory lengthening in Friulian. Probus 2, 31-46.

Inkelas, S., Cho, Y.M.Y., 1993. Inalterability as prespecification. Language 69, $529-574$.

Iverson, G.K., Salmons, J.C., 2011. Final laryngeal neutralization and final devoicing, in: van Oostendorp, M., Ewen, C.J., Hume, E., Rice, K. (Eds.), The Blackwell companion to phonology, Blackwell Publishing, Oxford.

Kavitskaya, D., 2002. Compensatory lengthening: phonetics, phonology, diachrony. Routledge, London, New York.

Kingston, J., 2007. The phonetics-phonology interface, in: de Lacy, P. (Ed.), The Cambridge Handbook of Phonology. Cambridge University Press, Cambridge, pp. 401-434.

Kiparsky, P., 2000. Opacity and cyclicity. The Linguistic Review 17, 351-367.

Kirchner, R., 1997. Contrastiveness and faithfulness. Phonology 14, 83-111.

Kraehenmann, A., 2001. Swiss German stops: geminates all over the word. Phonology 18, 109-145.

Kraehenmann, A., 2003. Quantity and prosodic asymmetries in Alemannic: synchronic and diachronic perspectives. Mouton de Gruyter, Berlin.

Krämer, M., 2009. The phonology of Italian. Oxford University Press. 
de Lacy, P., 2002. The interaction of tone and stress in Optimality Theory. Phonology 19, 1-32.

de Lacy, P., 2006. Markedness: reduction and preservation in phonology. Cambridge University Press, Cambridge.

Lahiri, A., Kraehenmann, A., 2004. On maintaining and extending contrasts: Notker's Anlautgesetz. Transactions of the Philological Society 102, 1-55.

Lombardi, L., 1995a. Laryngeal features and laryngeal neutralization. Garland Publishing, New York, London.

Lombardi, L., 1995b. Laryngeal features and privativity. The Linguistic Review $12,35-60$.

Lombardi, L., 2001. Why Place and Voice are different: constraint-specific alternations in Optimality Theory, in: Lombardi, L. (Ed.), Segmental phonology in Optimality Theory: constraints and representation, Cambridge University Press, Cambridge. pp. 13-45.

Loporcaro, M., 2007. Facts, theory and dogmas in historical linguistics: vowel quantity from Latin to Romance, in: Salmons, J.C., Dubenion-Smith, S. (Eds.), Historical linguistics 2005: selected papers from the 17th International Conference on Historical Linguistics, Madison, Wisconsin, John Benjamins, Amsterdam. pp. 311-336.

Loporcaro, M., 2011a. Phonological processes, in: Maiden et al. (2011). pp. 109154. pp. 109-154.

Loporcaro, M., 2011b. Syllable, segment and prosody, in: Maiden et al. (2011). pp. 50-108. pp. 50-108.

Maiden, M., Smith, J.C., Ledgeway, A. (Eds.), 2011. The Cambridge history of the Romance languages. Volume 1: Structures. Cambridge University Press, Cambridge.

Martinet, A., 1955. Economie des changements phonétiques. Francke, Bern.

Mascaró, J., 1987. A reduction and spreading theory of voicing and other sound effects. MS., Universitat Autònoma de Barcelona. Published (1995) in Catalan Working Papers in Linguistics 4.267-328. 
McCarthy, J.J., 2007. Hidden generalizations: phonological opacity in Optimality Theory. Number 1 in Advances in Optimality Theory, Equinox.

Mielke, J., 2007. The emergence of distinctive features. Oxford University Press, Oxford.

Miotti, R., 2002. Friulian. Journal of the International Phonetic Association 32, 237-247.

Miotti, R., 2007. Le varietà di Dignano, Flaibano e Sedegliano nel contesto dei dialetti friulani: aspetti fonologici, in: Vicario (2007). pp. 71-118. pp. 71-118.

Montreuil, J.P., 2010. Multiple opacity in Eastern Regional French, in: Colina, S., Olarrea, A., Carvalho, A.M. (Eds.), Romance Linguistics 2009: Selected Papers fron the 39th Linguistic Symposium on Romance Languages (LSRL), Tucson, Arizona, March 2009, John Benjamins, Amsterdam. pp. 153-166.

Morin, Y.C., 1992. What are the historical sources of vowel lengthening in Friulian? Probus 4, 155-182.

Morin, Y.C., 2003. Syncope, apocope, diphthongaison et palatalisation en galloroman: problèmes de chronologie relative, in: Sánchez Miret, F. (Ed.), Actas del XXIII Congreso Internacional de Lingüística y Filología Románica, Max Niemeyer Verlag, Tübingen. pp. 113-169.

Morén, B., 2001. Distinctiveness, coercion, and sonority: a unified theory of weight. Routledge, London, New York.

Morén, B., 2006. Consonant-vowel interactions in Serbian: Features, representations and constraint interactions. Lingua 116, 1198-1244.

Morén, B., 2007. The division of labour between segment-internal structure and violable constraints, in: Blaho et al. (2007). pp. 313-344. pp. 313-344.

Nevins, A., 2010. Locality in vowel harmony. Number 55 in Linguistic Inquiry Monograph, MIT Press, Cambridge, MA.

Odden, D., 1994. Adjacency parameters in phonology. Language 70, 289-330.

van Oostendorp, M., 2000. Phonological projection: a theory of feature content and prosodic structure. Number 47 in Studies in Generative Grammar, Mouton de Gruyter, Berlin. 
van Oostendorp, M., 2003. Ambisyllabicity and fricative voicing in West Germanic dialects, in: Féry, C., van de Vijver, R. (Eds.), The syllable in Optimality Theory, Cambridge University Press, Cambridge. pp. 304-337.

van Oostendorp, M., 2008. Incomplete devoicing in formal phonology. Lingua $118,1362-1374$.

Piggott, G.L., 1992. Variability in feature dependency: The case of nasality. Natural Language \& Linguistic Theory 10, 33-77.

Prieto i Vives, P., 2000. Vowel lengthening in Milanese, in: Repetti (2000). pp. 255-272. pp. 255-272.

Prince, A.S., Smolensky, P., 1993. Optimality Theory: Constraint Interaction in Generative Grammar. Technical Report. Rutgers University Center for Cognitive Science and University of Colorado, Boulder.

Pye, S., 1986. Word-final devoicing of obstruents in Russian, in: Hawkins, S. (Ed.), Cambridge papers in phonetics and experimental linguistics, Cambridge University Press, Cambridge. pp. 1-10.

Pöchtrager, M., 2006. The structure of length. Ph.D. thesis. University of Vienna. Vienna.

Reiss, C., 2007. Modularity in the sound domain: implications for the purview of Universal Grammar, in: Reiss, C., Ramchand, G. (Eds.), The Oxford handbook of linguistic interfaces. Oxford University Press, Oxford, pp. 53-80.

Repetti, L., 1992. Vowel length in Northern Italian dialects. Probus 4, 155-182.

Repetti, L., 1994. Degenerate syllables in Friulian. Linguistic Inquiry 25, 186193.

Repetti, L. (Ed.), 2000. Phonological theory and the dialects of Italy. Number 212 in Current Issues in Linguistic Theory, John Benjamins, Amsterdam.

Rice, K., 1996. Default variability: The coronal-velar relationship. Natural Language \& Linguistic Theory 14, 493-543.

Rice, K., 2003. Featural markedness in phonology: variation, in: Cheng, L., Sybesma, R. (Eds.), The second Glot International state-of-the-article book: the latest in linguistics, Mouton de Gruyter, Berlin. pp. 389-430. 
Rice, K., 2005. Liquid relationships. Toronto Working Papers in Linguistics 24, 31-44.

Rice, K., Avery, P., 1989. On the relation between sonorancy and voicing, in: Brunson, B., Burton, S., Wilson, T. (Eds.), Toronto Working Papers in Linguistics, pp. 65-82.

Rubach, J., 1994. Affricates as strident stops in Polish. Linguistic Inquiry 25, 119-143.

Rubach, J., 2008. Prevocalic faithfulness. Phonology 25, 433-468.

Sanga, G., 1988. La lunghezza vocalica nel milanese e la coscienza fonologica dei parlanti. Romance Philology 41, 290-297.

Schane, S.S., 1984. The fundamentals of particle phonology. Phonology 1, 129155.

Scheer, T., 2011. Issues in the development of generative phonology, in: Kula, N.C., Botma, B., Nasukawa, K. (Eds.), The Continuum companion to phonology, Continuum, London. pp. 396-446.

Seiler, G., 2009. Sound change or analogy? Monosyllabic lengthening in German and some of its consequences. The Journal of Comparative Germanic Linguistics 12, 229-272.

Shrager, M., 2002. Neutralization of word-final voicing in Russian. Journal of the Acoustical Society of America 112, 2419.

Slowiaczek, L., Dinnsen, D.A., 1985. On the neutralizing status of Polish wordfinal devoicing. Journal of Phonetics 13, 325-341.

Torres-Tamarit, F., forthcoming. Compensatory and opaque vowel lengthening in Harmonic Serialism, in: McCarthy, J.J., Pater, J. (Eds.), Harmonic Grammar and Harmonic Serialism, Equinox, London.

Trigo, R.L., 1988. The phonological behavior and derivation of nasal glides. Ph.D. thesis. Massachusetts Institute of Technology. Cambridge, MA.

Trubetzkoy, N.S., 1939. Grundzüge der Phonologie. Number 7 in Travaux du Cercle lingquistique de Prague, Le cercle linguistique de Prague, Prague. 
Uffmann, C., 2009. To (bi) or not to (bi). Presentation at the Privative Project workshop, Old World Conference in Phonology 6, Edinburgh.

Vanelli, L., 1979. L'allungamento delle vocali in friulano. Ce fastu? 55, 66-76.

Vanelli, L., 1986. La fonologia dei prestiti in friulano, in: Raetia antiqua et moderna: W. Theodor Elwert zum 80. Geburtstag, Niemeyer, Tübingen. pp. 355376.

Vaux, B., Wolfe, A., 2009. The appendix, in: Raimy, E., Cairns, C. (Eds.), Contemporary views on architecture and representations in phonology, MIT Press, Cambridge, MA. pp. 101-144.

Vicario, F. (Ed.), 2007. Ladine loqui: Atti del IV Colloquium Retoromanistisch. Società Filologica Friulana, Udine.

Videsott, P., 2001. Vokallängen im Norditalienischen und im Dolomitenladinischen, in: Wunderli, P., Werlen, I., Grünert, M. (Eds.), Italica-RaeticaGallica. Studia linguarum litterarum artiumque in honorem Ricarda Liver. Francke, Tübigen, Basel, pp. 151-168.

Warner, N., Jongman, A., Sereno, J., Kemps, R.R., 2004. Incomplete neutralization and other sub-phonemic durational differences in production and perception: evidence from Dutch. Journal of Phonetics 32, 251-276.

Weber Wetzel, E., 2002. Il dialetto di Casale Corte Cerro. Contributo alla conoscenza delle parlate del Cusio. Edizioni dell'Orso, Alessandria.

Wetzels, W.L., Mascaró, J., 2001. The typology of voicing and devoicing. Language $77,207-244$.

Yamamoto, S., 1993. Alcuni ampliamenti dei casi dell'allungamento vocalico nel friulano, in: Vanelli, L., Zamboni, A. (Eds.), Per Giovan Battista Pellegrini. Scritti degli allievi padovani, Unipress, Padova. pp. 645-655.

Yu, A.C.L., 2007. A natural history of infixation. Oxford University Press, Oxford.

Zec, D., 1988. Sonority constraints on prosodic structure. Ph.D. thesis. Stanford University. Stanford. 